\title{
The Role of Gut Microbiota in Atherosclerosis and Hypertension
}

\begin{abstract}
Junli Ma and Houkai Li*
Functional Metabolomic and Gut Microbiome Laboratory, Institute of Interdisciplinary Integrative Medicine Research, Shanghai University of Traditional Chinese Medicine, Shanghai, China
\end{abstract}

In recent years, accumulating evidence has indicated the importance of gut microbiota in maintaining human health. Gut dysbiosis is associated with the pathogenesis of a number of metabolic diseases including obesity, type 2 diabetes mellitus (T2DM), nonalcoholic fatty liver disease (NAFLD), and cardiovascular diseases (CVDs). Indeed, CVD has become the leading cause of death worldwide, especially in developed countries. In this review, we mainly discuss the gut microbiota-involved mechanisms of CVD focusing on atherosclerosis and hypertension, two major risk factors for serious CVD. Then, we briefly discuss the prospects of gut microbiota-targeted therapeutic strategies for the treatment of CVD in the future.

Keywords: gut microbiota, cardiovascular disease, atherosclerosis, TMAO, bile acids, hypertension, SCFAs

OPEN ACCESS

Edited by:

Li-Long Pan,

Fudan University, China

Reviewed by:

Martina Montagnana,

Università degli Studi di Verona, Italy

Ru Yan,

University of Macau, Macau

*Correspondence:

Houkai L

houkai1976@126.com

Specialty section:

This article was submitted to

Inflammation Pharmacology,

a section of the journal

Frontiers in Pharmacology

Received: 04 May 2018 Accepted: 06 September 2018

Published: 25 September 2018

Citation:

Ma J and Li H (2018) The Role of Gut Microbiota in Atherosclerosis and Hypertension.

Front. Pharmacol. 9:1082. doi: 10.3389/fphar.2018.01082

\section{INTRODUCTION}

Gut microbiota is the collection of bacteria that inhabit in the gastrointestinal tract producing a diverse ecosystem about $10^{14}$ microorganisms (Kamada et al., 2013). The majority of the gut microbiota is composed of five phyla, namely Bacteroidetes, Firmicutes, Actinobacteria, Proteobacteria, and Cerrucomicrobia, in which the relative abundance of Bacteroidetes and Firmicutes phyla is $>90 \%$ (Qin et al., 2010). The homeostasis of gut microbiota is critical for maintaining human health (Hansen et al., 2015; Kamo et al., 2017; Tang et al., 2017), with gut dysbiosis contributing to the development of various diseases including cardiovascular disease (CVD; Wang et al., 2011; Emoto et al., 2017), obesity (Ley et al., 2006; Henao-Mejia et al., 2012), type 2 diabetes mellitus (T2DM; Cani et al., 2008; Khan et al., 2014; Pedersen et al., 2016), nonalcoholic fatty liver disease (NAFLD; Mouzaki et al., 2013; Zhu et al., 2013), and even some types of cancer (Gopalakrishnan et al., 2018; Tilg et al., 2018).

Cardiovascular disease is the leading cause of death worldwide, especially in developed countries, and encompasses multiple disorders including atherosclerosis, hypertension, stroke, and heart failure (Mozaffarian et al., 2016). Although genetic contributions are intimately involved, other factors such as nutrition and gut microbiota have also been implicated as the main risk factors for developing CVD. Wang et al. (2011) reported the gut microbiota-dependent mechanism of CVD, highlighting the intricate relationship between gut microbiota and CVD. Recently, gut dysbiosis has been recognized as an important factor contributing to the development of atherosclerosis and hypertension, two major risk factors for CVD (Lau et al., 2017). Consequently, gut microbiota-targeted therapy is a promising strategy to treat CVD (Koopen et al., 2016; Anbazhagan et al., 2017; Santisteban et al., 2017).

In this review, we extensively retrieved the publications on the topics of gut microbiota and CVD mainly published within the past 10 years through PubMed. We discuss the roles of gut microbiota implicated in the development of CVD, especially focusing on atherosclerosis and hypertension, and briefly summarize the recent advances of gut microbiota-targeted therapies for CVD. 


\section{GUT MICROBIOTA AND ATHEROSCLEROSIS}

Atherosclerosis is the major risk factor for CVD, which is characterized by accumulation of cholesterol and recruitment of macrophages into artery walls, contributing to the formation of atherosclerotic plaques (Gui et al., 2012). Interestingly, recent studies have suggested that gut dysbiosis can also contribute to the development of atherosclerosis (Drosos et al., 2015; Gregory et al., 2015; Jie et al., 2017). Using shotgun sequencing of the gut metagenome in patients with or without symptomatic atherosclerosis, scientists found that the relative abundance of Roseburia and Eubacterium was lower, while Collinsella was higher in atherosclerosis patients compared to healthy controls (Karlsson et al., 2012). In addition, Akkermansia muciniphila was found to improve gut barrier functions and exert protective effects against atherosclerosis (Li et al., 2016). Although metaanalysis showed no significant benefit in coronary artery disease patients treated with antibiotics (Andraws et al., 2005), nevertheless, evidence is accumulating which indicates that gut microbiota play a causative role in atherosclerotic by modulating inflammation and the production of microbial metabolites (Kasahara et al., 2017).

\section{Gut Dysbiosis and Inflammation in Atherosclerosis}

Inflammation is commonly involved in a number of diseases (Xu et al., 2003; Ding et al., 2010), including atherosclerosis, which is a classical chronic inflammatory disease (Gui et al., 2012). Gut epithelium is the first barrier of the host, which protects against the invasion of pathogens (Desai et al., 2016). Given its critical role in preventing the translocation of intestinal content, mainly bacterial components, the integrity of the gut barrier is essential for maintaining the health of the host. Intestinal permeability is associated with reduced expression of tight junction proteins, including zonula occludens-1 (ZO-1), claudin-1, and occludin, and an imbalance between intestinal epithelial cell death and regeneration (Wang H. et al., 2014; Chen W.Y. et al., 2017). If the intestinal epithelial barrier is impaired, the invasion of pathogen associated molecular patterns (PAMPs) drives an immune response and results in systemic and tissue-specific inflammation. Accordingly, impairments to the gut barrier integrity induced by gut dysbiosis have been suggested as risk factor for chronic inflammation in various diseases. It is noteworthy that lipopolysaccharide (LPS) and peptidoglycan are microbial components that are recognized as risk factors for CVD.

Lipopolysaccharide is a cell wall component of Gram-negative $[G(-)]$ bacteria, which has been extensively studied as it is one of the PAMPs involved in CVD risk. The association between LPS and CVD was first proposed in 1999 by measuring plasma endotoxin levels in the clinic (Wiedermann et al., 1999). Subsequently, the relationship was gradually confirmed by multiple experiments by different research groups (Niebauer et al., 1999; Stoll et al., 2004; Miller et al., 2009; Mitra et al., 2015). For example, in one study, it was concluded that the level of circulating endotoxemia was most notable in patients with the highest CVD burden (McIntyre et al., 2011). Cani et al. (2007) found that gut dysbiosis suppressed the expression of tight junction proteins, leading to an increase in intestinal permeability and subsequently the translocation of LPS into the blood (Harris et al., 2012). Gut dysbiosis-derived LPS may play important roles by modulation of Toll-like receptors (TLRs) and their downstream targets (Libby, 2002; Chacon et al., 2017). As part of the pattern-recognition receptors family, TLRs can recognize bacterial products and modulate the host immune system (Akira and Takeda, 2004; Akira et al., 2006). Circulating LPS can bind to cell-surface-receptor complexes composed of TLR4 and its coreceptors cluster of differentiation 14 (CD14; Neves et al., 2013). Using TLR4 and LDL receptors double knockout mice, Ding et al. (2012) found that a TLR4 deficiency reduced atherosclerosis without effect on inflammation (Ding et al., 2012). Consistently, clinical investigations have revealed that upregulation of TLRs was associated with inflammatory activation in human atherosclerosis, and promoted the development of atherosclerosis (Xu et al., 2001; Edfeldt et al., 2002). However, a meta-analysis in 2012 indicated that Asp299Gly, a TLR4 polymorphism, did not play an obvious role in the development of atherosclerosis (Zhang et al., 2012). Moreover, the binding of LPS to TLR4 activated its downstream pathways including MYD88 and nuclear factor kappa B (NF- $\mathrm{B}$ ), contributing to the increased production of pro-inflammatory cytokines such as IL-6, IL1, IL-27, and tumor necrosis factor-alpha (TNF- $\alpha$ ), leading to an increased risk of developing CVD (Barton and Kagan, 2009; Guzzo et al., 2012). Bjorkbacka et al. (2004) showed that a deficiency of MyD88 reduced atherosclerosis by decreasing macrophage recruitment (Bjorkbacka et al., 2004). The main interactions between gut microbiota and inflammation are shown schematically in Figure 1.

In addition, another bacterial PAMP, peptidoglycan (PG), was also found to be associated with CVD risk by impairing the intestinal epithelial barrier. PG is a minor cell wall component of $[G(-)]$ bacteria; however, it is also a major component of Gram-positive $[\mathrm{G}(+)]$ bacteria. Using metagenomic sequencing, scientists found that patients with atherosclerosis had enrichment of genes that encoded PG synthesis (Karlsson et al., 2012). Indeed, pro-inflammatory bacterial PG was observed in atherosclerotic arteries and associated with vulnerable plaques (Laman et al., 2002). Through PG recognition, the nucleotide-binding oligomerization domain (NOD) proteins NOD1 and NOD2 promote intracellular bacteria clearance through a program involving NF- $\mathrm{KB}$ and mitogen-activated protein kinase (MAPK) signaling pathways (Philpott et al., 2014). Studies in Nod2deficient mice revealed that NOD2 was a critical regulator of intestinal bacterial immunity and helps to maintain the integrity of the gut barrier (Kobayashi et al., 2005). In recent years, scientists have investigated the potential role of NOD1 in atherosclerosis using Nod1 knockout mice. Data showed that knockout of apolipoprotein E and Nod1 in mice significantly reduced the development of atherosclerotic lesions (Kanno et al., 2015). Additionally, there are other PAMPs that can promote inflammatory processes through the engagement of host pattern recognition receptors (PRRs), such as $\mathrm{CpG}$ 


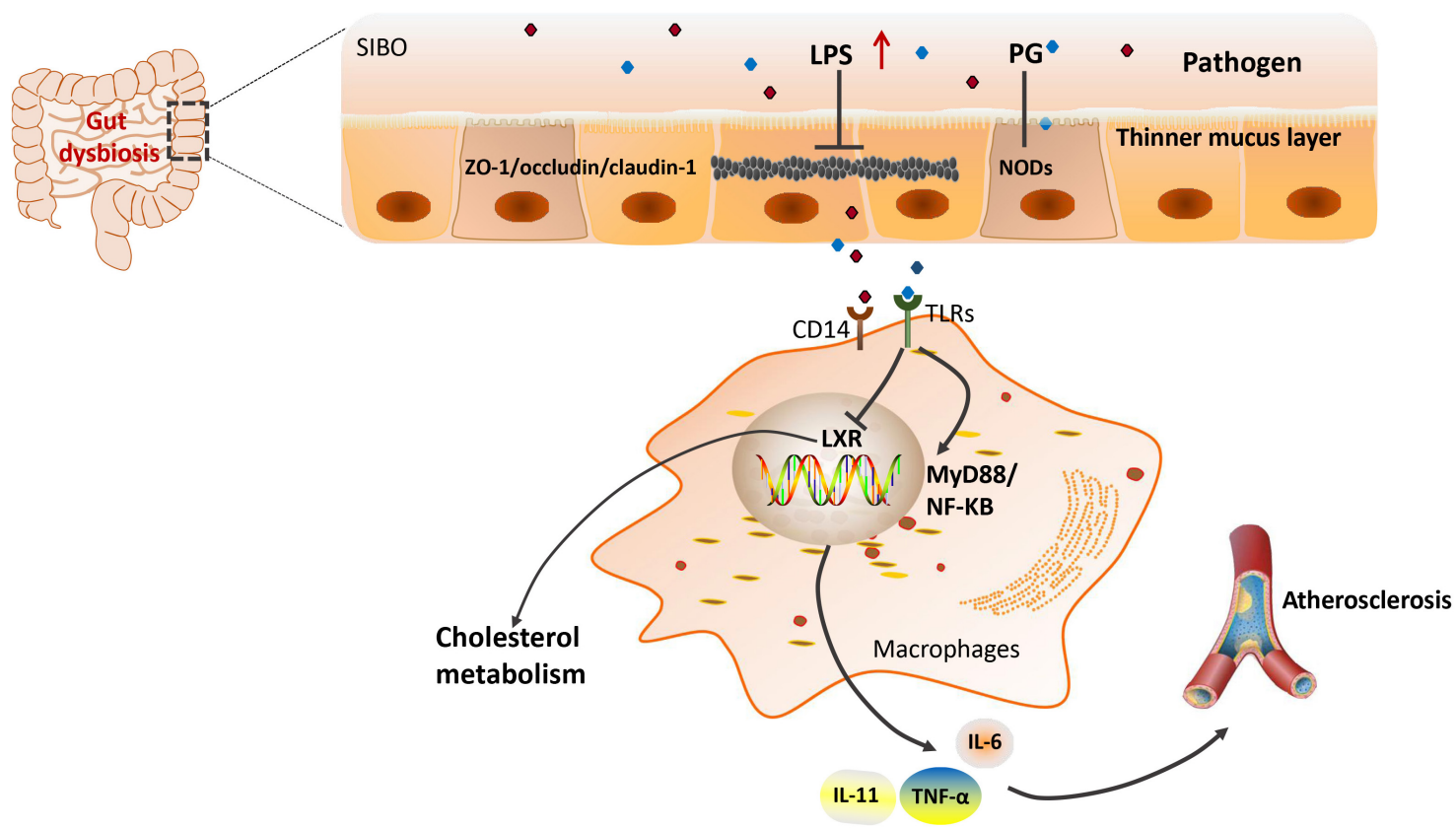

FIGURE 1 | Gut microbiota and LPS-induced inflammation in atherosclerosis. LPS, lipopolysaccharides; ZO-1/occludin, two tight junction proteins; CD14, the monocyte differentiation antigen; TLR4, Toll-like receptor 4; LXR, liver X receptor; MyD88, myeloid differentiation primary response gene 88; NF-kB, nuclear factor kappa B; IL, interleukin; TNF- $\alpha$, tumor necrosis factor-alpha; PG, peptidoglycan; NODs, nucleotide-binding oligomerization domain proteins.

oligodeoxynucleotides flagellin, lipopeptides, and so on (Kholy et al., 2015). Collectively, all of the evidence suggests that functional changes in the gut microbiota might be involved in the atherosclerosis risk. Although the vast majority of studies revealed that pathogenic bacteria contributed to atherosclerosis pathogenesis, two antibiotic trials reported controversial benefits of antibiotic therapy in CVD (Caligiuri et al., 2001; Munford, 2016).

\section{Gut Microbial Metabolites in Atherosclerosis}

In addition to gut dysbiosis-related inflammation, increasing evidence has revealed that gut microbiota-derived metabolites play essential roles in the development of CVD (Brown and Hazen, 2015; Bergeron et al., 2016). A variety of metabolites are derived from the gut microbiota, as well as co-metabolism of gut microbiota such as amines methylamines, polyamines, shortchain fatty acids (SCFAs), trimethylamine $\mathrm{N}$-oxide (TMAO), and secondary bile acids (BAs). SCFAs are a group of wellestablished gut microbial metabolites that are critically involved in metabolic diseases (Li et al., 2017). Recent advances detailing their involvement in atherosclerosis in both human and animal models have been extensively reviewed (Brown and Hazen, 2018). Therefore, in the current review, we mainly focused on the roles of TMAO and secondary BAs in atherosclerosis.

\section{TMAO and Atherosclerosis}

Dietary phosphatidylcholine or L-carnitine is metabolized by gut microbiota into trimethylamine (TMA) in the intestine
(Brown and Hazen, 2015). It is a precursor of TMAO, which is transported to liver and oxidized by flavin monooxygenase 3 (FMO3), one member of the hepatic FMO enzymes family, leading to the production of TMAO (Wang Z. et al., 2014). Hepatic knockdown of FMO3 in mice using an antisense oligonucleotide decreased circulating TMAO levels and attenuated atherosclerosis through stimulating basal metabolism and activating macrophage reverse cholesterol transport (RCT; Miao et al., 2015; Shih et al., 2015; Warrier et al., 2015). It was also found that plasma levels of gut microbial dietary phosphatidylcholine metabolites and TMAO that produced related molecules (L-carnitine and $\gamma$-butyrobetaine) were associated with the risk of CVD (Koeth et al., 2014; Chen K. et al., 2017; Guasch-Ferre et al., 2017). The higher level of plasma TMAO was correlated with atherosclerosis formation and the extent of the atherosclerotic plaque area (Wang et al., 2011). Consistently, a prospective and observational clinical study on patients with or without chronic heart failure has shown that plasma levels of TMAO were positively correlated with the risk of chronic heart failure (Troseid et al., 2015). These findings suggest that circulating levels of TMAO are important risk factors for the pathogenesis of CVD.

Given the roles of TMAO in the pathogenesis of CVD, the underlying mechanisms have been extensively investigated. To explore potential mechanisms by which TMAO might promote atherosclerosis, a dietary choline supplement was administered to $\mathrm{ApoE}^{-/-}$mice, in which the expression of CD36 and steroid receptor RNA activator 1 (SR-A1), two macrophage scavenger receptors implicated in atherosclerosis, was measured. The results revealed elevated levels of CD36 and 
SR-A1 in the macrophages of TMAO-treated mice compared to normal controls, and antibiotic intervention reduced the formation of foam cells by decreasing TMA production (Wang et al., 2011). However, no significant impact of TMAO on foam cell formation was observed in mouse macrophages. In contrast, TMAO can lead to atherosclerosis by suppressing RCT and modulating the activity of cholesterol transporters in macrophages (Koeth et al., 2013). In addition, TMAO administration could suppress levels of liver BA synthetase (Cyp7a1 and Cyp27a1) and BA transporters (Oatp1, Oatp4, Mrp2, and Ntcp), leading to a disorder of BA-related pathways and atherosclerosis (Koeth et al., 2013), suggesting that the atherosclerotic promoting effect of TMAO is also associated with the variation in BA metabolism. Farnesoid $\mathrm{X}$ receptor (FXR) is an important nuclear receptor that controls BA metabolism, which can also regulate the expression of hepatic FMO3, resulting in an alteration in TMAO production (Bennett et al., 2013). An FXR agonist inhibited the expression of CYP7A1 and CYP8B1 in ApoE ${ }^{-/-}$mice and protected mice against atherosclerosis (Mencarelli et al., 2009; Bennett et al., 2013; Miyazaki-Anzai et al., 2014; Miao et al., 2015). Recently, Ma et al. (2017) found that TMAO upregulated the expression of vascular cell adhesion molecule-1 (VCAM-1) and activated protein kinase $\mathrm{C}(\mathrm{PKC})$ and NF- $\mathrm{B}$, highlighting that TMAO may speed up the development of atherosclerosis by inducing endothelial cell dysfunction and by increasing monocyte adhesion. Additionally, the direct exposure of platelets to TMAO increased stimulus-dependent platelet activation by elevating $\mathrm{Ca}^{2+}$ release from intracellular stores, contributing to the increased risks of thrombosis and plaque instability (Zhu et al., 2016). Generally, TMAO accelerates the development of atherosclerosis by promoting cholesterol influx, inhibiting cholesterol efflux, blocking the BA pathway, and/or causing excessive activation of platelets. All of these findings confirmed TMAO as a biomarker for CVD risk and a promoter of atherosclerotic diseases (Senthong et al., 2016a,b; Zheng et al., 2016). TMAO is regarded as one of the most promising metabolites that may not only be an independent risk factor for CVD, but also a potential therapeutic target for CVD on the basis of a large amount of experimental and clinical data. However, inconsistent results were also observed, especially in large population observations (Dalmeijer et al., 2008; Nagata et al., 2015; Meyer et al., 2016). Choline is generally regarded as a dietary source of TMAO; however, in a cohort study, there was no clear evidence of significant associations between choline intake and the risk of developing CVD (Nagata et al., 2015). Likewise, in ApoE(-/-)mice, L-carnitine administration resulted in a significant increase in circulating TMAO levels, which surprisingly was inversely correlated with aortic lesion size(Collins et al., 2016). Unfortunately, several large population studies conducted by different countries have demonstrated that dietary choline and betaine intake was not associated with the pathogenesis of CVD (Bidulescu et al., 2007; Dalmeijer et al., 2008). Consequently, more studies are needed to confirm the exact roles of TMAO in atherosclerosis, as well as the validation of its therapeutic potential by targeting TMAO-producing bacteria or enzymes.

\section{Bile Acids and Atherosclerosis}

Bile acids are another group of gut microbiota-derived metabolites involved in various metabolic diseases (Kuipers et al., 2014; Parseus et al., 2017), which are stored in the gallbladder and released into the intestine to facilitate the absorption of dietary lipids and fat-soluble vitamins. Primary BAs are synthesized from cholesterol in the liver and mainly include cholic acid (CA) and chenodeoxycholic acid (CDCA). Primary BAs are usually metabolized into secondary BAs including deoxycholic acid (DCA) and lithocholic acid (LCA), hyodeoxycholic acid, and ursodeoxycholic acid through gut microbiota-derived enzymes (Midtvedt, 1974; Russell, 2003). Previous studies reported that germ-free mice had higher levels of primary BAs, but non-detectable secondary BAs in the enterohepatic system (Sayin et al., 2013). It was found that suppression of hepatic BA biosynthesis could inhibit the HFD-induced gut microbiome alterations, which highlights the liver-BA-gut microbiome metabolic axis (Zheng et al., 2017). Thus, there is a bidirectional relationship between gut microbiota and BA metabolism (Jones et al., 2014).

Bile acids are also important signaling molecules that modulate host metabolism and energy expenditure processes (Dawson and Karpen, 2015; Joyce and Gahan, 2017). Bile salts can be diversified into biologically active species by gut microbiota that can survive in the bile salt-rich microenvironment. Gut microbiota-mediated BA metabolism in CVD has been well reviewed recently (Brown and Hazen, 2018). Nevertheless, to date, the role of BAs in CVD development is still poorly understood so far. It is well recognized that BAs can promote the development of atherosclerosis mainly through bile-salt hydrolase (BSH) and BA receptors (Lefebvre et al., 2009; Ridlon et al., 2016). The C24 N-acyl bond of glycine-conjugated or taurine-conjugated bile salts can be hydrolyzed into free BAs by BSH (Klaassen and Cui, 2015). In addition to deconjugation, the BA pool can also be chemically diversified by bacteriaderived $7 \alpha$-dehydroxylase and $7 \beta$-dehydroxylase. The produced secondary BAs enter the portal circulation to function as signaling molecules with profound effects on host physiology and pathology (Lepercq et al., 2004). Bacteria-mediated BSH activity can affect the processes underlying the pathogenesis of atherosclerosis by increasing cholesterol accumulation, foam cell formation, and the size of the atherosclerotic plaque (Hansson et al., 2006). BSH is present in a wide range of bacteria such as Methanobrevibacter smithii, Clostridium, Enterococcus, and so on (Jones et al., 2012a; Tremaroli and Backhed, 2012).

In addition to BA itself, BA receptors are indispensable in mediating their biological functions. Farnesoid X-activated receptor (FXR) is one of the most important and well-studied $\mathrm{BA}$ receptors that regulates glucose and lipid metabolism by affecting transcription of genes that are involved in primary BA synthesis (Makishima et al., 1999; Wahlstrom et al., 2016). The critical role of FXR in mediating cholesterol metabolism was elucidated by using $\mathrm{FXR}^{-/-}$mice which have increased plasma high density lipoprotein (HDL) cholesterol, non-HDL cholesterol and triglyceride levels compared to wild-type mice (Lambert et al., 2003). In a previous study, loss of functional FXR in apolipoprotein E-deficient (ApoE-/-) mice, a mouse model 
of atherosclerosis, resulted in more severe lipid metabolism defects and enhanced aortic plaque formation (Hanniman et al., 2005). Furthermore, FXR deficiency can result in a decrease of plasma low-density lipoprotein cholesterol and CD36 expression in macrophages, leading to a reduced risk of atherosclerosis in LDLR knockout (LDLR ${ }^{-/-}$) mice (Zhang et al., 2006). On the other hand, research indicates that activation of FXR with an agonist can protect against atherosclerosis in $\mathrm{LDLR}^{-/-}$and $\mathrm{ApoE}^{-/-}$mice, which may be associated with suppression of genes involved in BAs synthesis (Hartman et al., 2009). The G protein-coupled BA receptor, also known as TGR5, is another important host $\mathrm{BA}$ receptor that is responsive to BAs ( $\mathrm{Li}$ and Chiang, 2015). Recent investigations have indicated that activation of TGR5 can inhibit atherosclerosis formation, an effect associated with a reduction of macrophage inflammation and lipid loading (Pols et al., 2011). Moreover, activation of TGR5 also contributes to enhanced energy expenditure and improved glycemic control (Watanabe et al., 2006). Pregnane X receptor (PXR) is another type of nuclear hormone receptor that regulates the expression of genes involved in the biosynthesis, transport, and metabolism of BAs, and can also be activated by secondary BAs such as LCA (Staudinger et al., 2001). Deletion of PXR attenuates the development of atherosclerosis in PXR and apoE double knockout $\left(\mathrm{PXR}^{-/-}\right.$and $\mathrm{ApoE}^{-/-}$) mice, which may be associated with the reduction of CD36 expression and lipid uptake in macrophages (Sui et al., 2011). It has been reported that activation of PXR by a PXR agonist increases the levels of atherogenic lipoproteins VLDL and LDL, and that PXR activation accelerates atherosclerosis in $\mathrm{ApoE}^{-/-}$mice (Zhou et al., 2009). In addition, the vitamin D3 receptor (VDR) is a sensor for bacteria-induced BA that is much more sensitive to LCA and its metabolite (3-oxo-LCA) than other nuclear receptors (Makishima et al., 2002). It has been found that macrophage VDR signaling attenuates atherosclerosis in mice in part by inhibiting the local renin-angiotensin system (Szeto et al., 2012). Finally, sphingosine-1-phosphate receptor 2 (S1PR2) can be activated by various conjugated BAs and then promotes atherosclerosis by regulating macrophage retention and inflammatory cytokine secretion (Studer et al., 2012), whereas S1PR2 knockdown attenuates atherosclerosis in $\mathrm{ApoE}^{-/-}$mice (Skoura et al., 2011).

In summary, gut microbiota-derived secondary BAs play important roles in the development of atherosclerosis through the modulation of various BA receptors such as FXR, PXR, TGR5, VDR, and S1PR2. This finding highlights the great potential for novel atherosclerosis therapy by targeting gut microbiota (Levi, 2016). The main mechanisms associated with gut microbiotaderived metabolites and atherosclerosis is shown schematically in Figure 2.

\section{GUT MICROBIOTA AND HYPERTENSION}

Hypertension is another important risk for CVD that is induced by both genetic susceptibility and environmental factors (Townsend et al., 2016). Given the increasing recognition of the role of gut microbiota in metabolic diseases (Karlsson et al., 2012; Tremaroli and Backhed, 2012; Jonsson and Backhed, 2017;
Yamashiro et al., 2017), the relationship between gut microbiota and hypertension has also been evaluated in recent years. In 1982, it was demonstrated that antibiotic treatment could produce a higher blood pressure, which implicated the probable involvement of gut microbiota in regulating blood pressure (Honour, 1982). In spontaneously hypertensive rats, Yang et al. (2015) observed a significant decrease in microbial richness and diversity, and an increase in the ratio of Firmicutes/Bacteroidetes. In another study, compared with conventionally raised (CONVR) mice, GF mice infused with AngII showed attenuation of the blood pressure increase in response to AngII, indicating that gut microbiota promotes AngII-induced vascular dysfunction and hypertension (Karbach et al., 2016). Accordingly, the gut microbiota is probably involved in the development of hypertension. Although the relationship and mechanism underlying gut microbiota and hypertension have not yet been fully elucidated, the existing evidence has highlighted the critical roles of SCFAs and oxidized low-density lipoprotein (ox-LDL) in hypertension.

\section{SCFAs and Hypertension}

Short-chain fatty acids (such as acetate, proprionate, and butyrate), which are derived from dietary fiber (mainly polysaccharides), play crucial roles in maintaining the homeostasis of the gut microbiome and host immunity (El Kaoutari et al., 2013; Canfora et al., 2015; Koh et al., 2016; Miyamoto et al., 2016). Interestingly, bacteria that metabolize polysaccharides into different types of SCFAs are specific (Rey et al., 2010). For instance, the major acetateproducing bacteria are Streptococcus spp., Prevotella spp., Bifidobacterium spp., Clostridiums pp., A. muciniphila, and so on (Rey et al., 2010). Propionate is generated from carbohydrate fermentation by Bacteroides spp., Salmonella spp., Dialister spp., Veillonella spp., Roseburia inulinivorans, Coprococcus catus, Blautia obeum, etc. (Louis and Flint, 2017), while butyrate is derived from Lachnospiraceae, Ruminococcaceae, and Acidaminococcaceae families (Duncan et al., 2002). Clinical evidence has shown that the abundance of butyrateproducing bacteria is associated with a lower blood pressure in obese pregnant women (Gomez-Arango et al., 2016). A recent study found that fiber and acetate supplementation improved gut dysbiosis, associated with an increase in Bacteroides acidifaciens, which may play a protective role in hypertension and heart failure in hypertensive mice (Marques et al., 2017).

The role of host G-protein-coupled receptors (GPCRs) in the development of hypertension has been well reviewed (Pluznick et al., 2013). To date, there are at least three GPCRs that are regulated by SCFAs including GPR41, GPR43, and GPR109A (Tan et al., 2017). SCFAs can stimulate host GPCRsregulated pathways to affect renin secretion and therefore blood pressure (Furusawa et al., 2013; Pluznick et al., 2013). One study has reported that GPR41 knockout mice exhibited systolic hypertension compared with wild-type mice, and that SCFAs lowered blood pressure by regulating endothelial GPR41 (Natarajan et al., 2016). Olfactory receptor 78 (Olfr78) is another type of GPCR expressed in the kidney, which can 


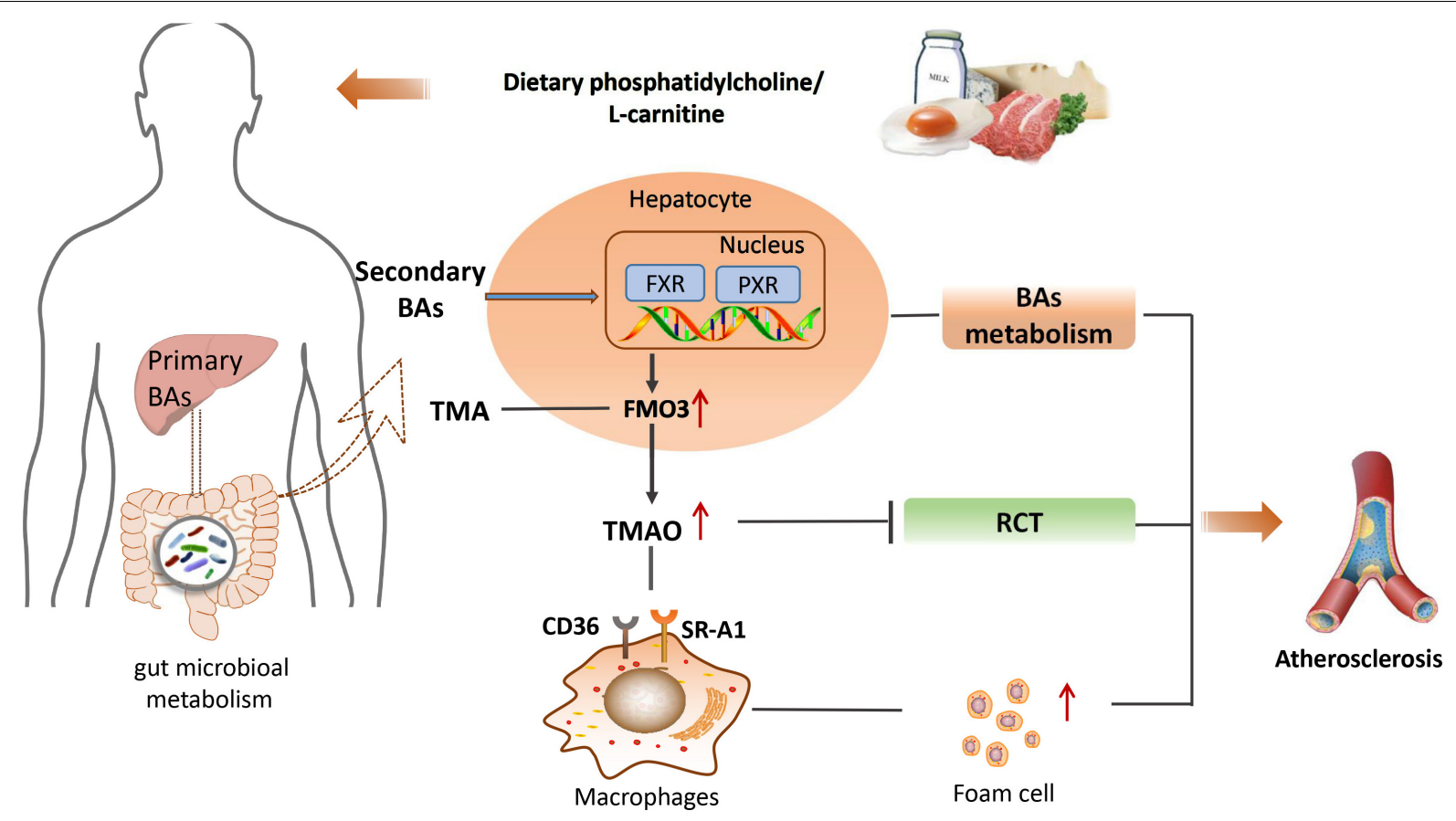

FIGURE 2 | The main mechanisms between gut microbiota-derived metabolites and atherosclerosis. BA, bile acids; TMA, trimethylamine; FXR, farnesoid X receptor; PXR, pregnane X receptor; FMO3, flavin monooxygenase 3; TMAO, trimethylamine N-oxide; CD36, the monocyte differentiation antigen; RCT, reverse cholesterol transport; SR-A1, steroid receptor RNA activator 1.

also be modulated by SCFAs such as acetate and propionate (Tan et al., 2017). In addition, both Olfr78 and GPR41 are expressed in smooth muscle cells of small resistance blood vessels (Pluznick et al., 2013). Propionate can induce vasodilation and produce an acute hypotensive response in mice through modulation of Olfr78 and GPR41 activity (Miyamoto et al., 2016). On the other hand, it was found that stimulation of GPR41 resulted in a reduction of the hypotensive response, and this effect could be opposed by stimulating Olfr78 (Pluznick, 2013). Interestingly, antibiotic treatment not only altered the composition of gut microbiota, but also increased blood pressure in Olfr78 knockout mice (Pluznick et al., 2013). In recent years, Reijnders et al. (2016) conducted a randomized doubleblind placebo-controlled trial, in which SCFAs and a number of metabolic parameters were measured. The inconsistent outcome was reported that the levels of SCFAs had no significant effects on energy or glucose homeostasis in humans (Reijnders et al., 2016). Overall, although all these findings revealed that gut microbiota may play important roles in modulating the host blood pressure through production of microbial SCFAs, the potential for SCFAs to be a therapeutic target for CVD needs to be confirmed by additional investigations in the future.

\section{Oxidized Low Density Lipoprotein (ox-LDL) and Hypertension}

Generally, the regulation of blood pressure depends on the magnitude of blood vessel vasoconstriction and vasodilation (Luscher and Barton, 1997). In addition to the regulation of various receptors, gut dysbiosis also contributes to hypertension through vasoconstriction mediated by oxidation of LDL (Packer et al., 2014).

Dysbiosis can promote the expression of pro-inflammatory cytokines and induce oxidative stress, which can stimulate Ox-LDL (Chawla et al., 2011; Peluso et al., 2012). Previous studies have shown that higher levels of oxLDL contribute to hypertension by inhibiting the production of nitric oxide (NO) and endothelin-1 (Subah Packer, 2007). NO is a well-established vasodilator that is produced through oxidation of L-arginine by NO synthase. Ox-LDL decreases the production of $\mathrm{NO}$ and reduces the degree of vasodilation (Ma et al., 2006). Moreover, endothelin-1 plays crucial roles in maintaining basic vascular tension and cardiovascular system homeostasis. Interestingly, the activity of endothelin-1 on blood vessels is concentrationdependent, that is, endothelin-1 produces vasodilatory effects at low concentrations by activating the endothelial receptor B (ETB) and promoting NO production, but produces vasoconstriction at high concentrations by increasing ox-LDL production in plaques and activating the endothelial receptor A (ETA; Boulanger and Luscher, 1990).

Although a causative relationship between gut dysbiosis and hypertension has been acquired (Kamo et al., 2017; Santisteban et al., 2017), the exact role of gut microbiota in mediating hypertension still requires further extensive investigation. The main mechanisms associated with gut microbiota and hypertension are shown schematically in Figure 3, together with a summary of microbial-derived metabolites and CVD development in Table $\mathbf{1 .}$ 


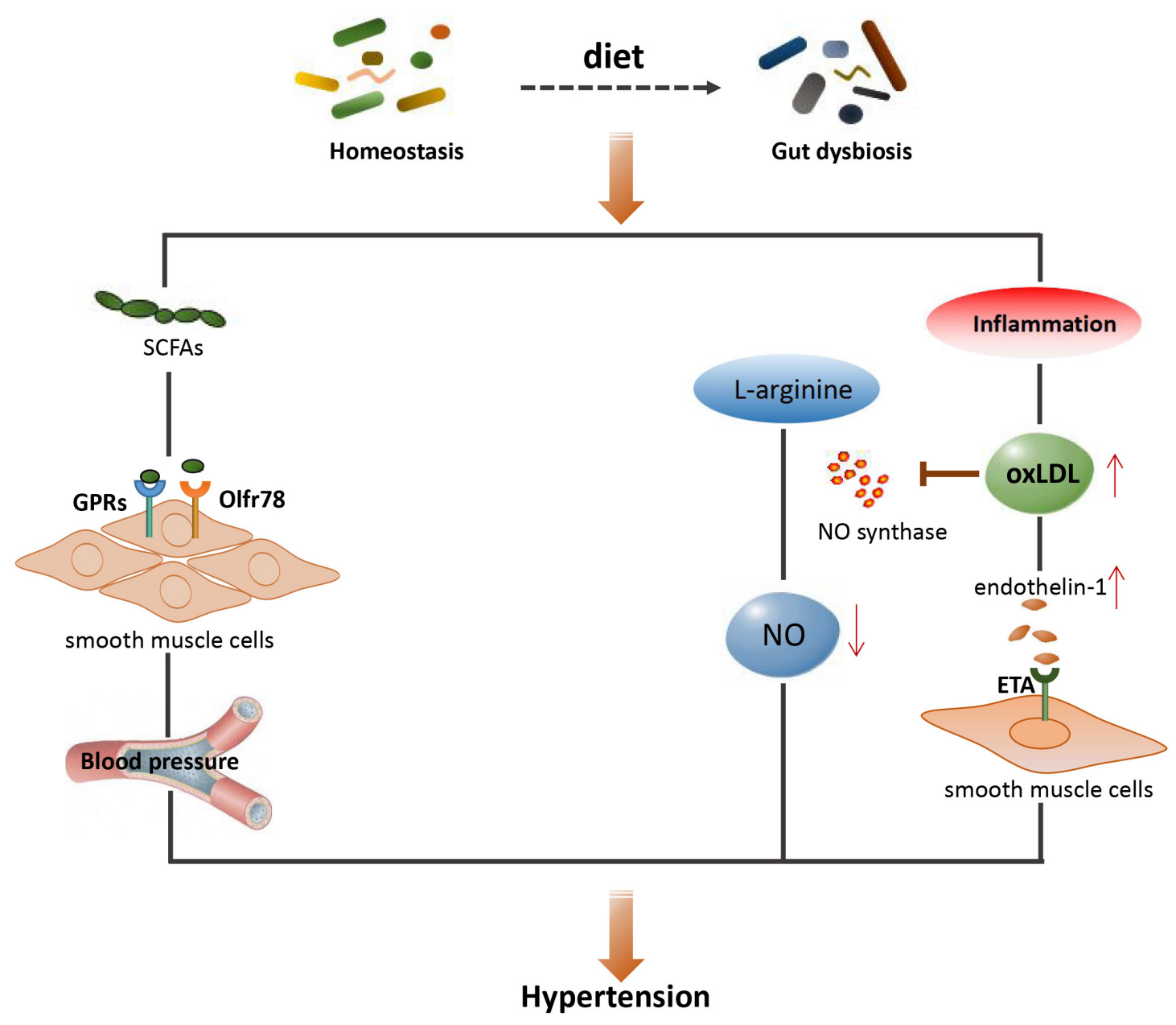

FIGURE 3 | The main mechanisms between gut microbiota and hypertension. SCFAs, short-chain fatty acids; GPRs, G-protein-coupled receptors; Olfr78, olfactory receptor 78; NO, nitric oxide; OxLDL, oxidized low density lipoprotein; ETA, endothelin receptor A.

\section{GUT MICROBIOTA-TARGETED THERAPY OF CVD}

Given the contributions of gut microbiota to the development of CVD, they have emerged as a potentially important target for CVD therapy (Daliri et al., 2017; He and Shi, 2017). The most frequently used approaches to manipulate the gut microbiota include probiotic, prebiotic, natural components, fecal transplantation, and so on.

Probiotic is a collection of bacteria with a wide range of beneficial effects on host metabolism (Sanders, 2008; Ettinger et al., 2014; Yoo and Kim, 2016). The widely used probiotics are Lactobacillus, Bifidobacterium, and Satreptococcus (Kailasapathy and Chin, 2000; Miura and Ohnishi, 2014). In a randomized double-blind clinical trial, Fuentes et al. (2013) found that a probiotic of Lactobacillus plantarum CECT 7527, 7528, and 7529 reduced circulating cholesterol levels and inhibited the formation of atherosclerotic plaques in hyper-cholesterol patients. In another randomized control study, subjects taking Lactobacillus reuteri NCIMB 30242 showed more significant reductions of LDL-C and total cholesterol levels compared to subjects given placebo capsules (Jones et al., 2012b). In addition, the benefits of probiotics of different Lactobacillus bacteria (Lactobacillus fermentum CECT5716 (LC40), Lactobacillus coryniformis CECT5711 (K8) and Lactobacillus gasseri CECT5714 (LC9) in the regulation of blood pressure have been investigated in spontaneously hypertensive rats, and it was found that longterm administration of these probiotics could reduce systolic blood pressure (Gomez-Guzman et al., 2015). A recent study has reported that the probiotic L. plantarum ECGC13110402 was well tolerated and can be used as an alternative or supplement to reduce cardiovascular risk (Costabile et al., 2017).

Prebiotic is a class of indigestible food ingredients with benefits via selectively stimulating the growth of "good" and suppressing the growth of "bad" bacteria in the intestinal tract (Gibson and Roberfroid, 1995). Prebiotic can usually cause specific changes in the composition of gut microbiota and exert beneficial effects on host metabolism. Recent investigations have 
TABLE 1 | Gut microbial-derived metabolites and CVD.

\begin{tabular}{|c|c|c|c|}
\hline Metabolite & Experimental models & Main observations & References \\
\hline \multirow[t]{15}{*}{ TMAO } & FMO3 knockdown mice & $\begin{array}{l}\text { The TMAO-generating enzyme FMO3 is a central regulator of } \\
\text { cholesterol balance }\end{array}$ & Warrier et al., 2015 \\
\hline & $\begin{array}{l}\text { Western diet (WD)-induced } \\
\text { obese mice }\end{array}$ & $\begin{array}{l}\text { Consumption of a WD increases circulating TMAO levels, which } \\
\text { contributes to cardiac dysfunction }\end{array}$ & Chen K. et al., 2017 \\
\hline & C57BL/6 mice & $\begin{array}{l}\text { TMAO promotes pathological process of atherosclerosis by impairing } \\
\text { endothelial self-repair capacity and enhancing monocyte adhesion }\end{array}$ & Ma et al., 2017 \\
\hline & Apoe-/- female mice & $\begin{array}{l}\text { Gut microbial metabolite } \gamma \text {-butyrobetaine is converted into TMA and } \\
\text { TMAO, and accelerates atherosclerosis }\end{array}$ & Koeth et al., 2014 \\
\hline & Apoe-/- mice & $\begin{array}{l}\text { Dietary choline or TMAO supplementation enhances atherosclerotic } \\
\text { lesion development }\end{array}$ & Wang et al., 2011 \\
\hline & Apoe-/- mice & $\begin{array}{l}\text { Dietary L-carnitine supplementation alters gut microbial composition, } \\
\text { enhances production of TMA/TMAO, and increases atherosclerosis }\end{array}$ & Koeth et al., 2013 \\
\hline & Germ-free mice & $\begin{array}{l}\text { Gut microbial metabolite TMAO enhances platelet hyperreactivity and } \\
\text { thrombosis risk }\end{array}$ & Zhu et al., 2016 \\
\hline & ApoE(-/-) mice & $\begin{array}{l}\text { L-carnitine intake and high plasma TMAO levels correlate with low aortic } \\
\text { lesions }\end{array}$ & Collins et al., 2016 \\
\hline & $\begin{array}{l}155 \text { patients with chronic heart } \\
\text { failure }\end{array}$ & TMAO is associated with survival of patients with chronic heart failure & Troseid et al., 2015 \\
\hline & 817 participants (young adults) & $\begin{array}{l}\text { TMAO may not significantly contribute to early atherosclerotic disease } \\
\text { risk }\end{array}$ & Meyer et al., 2016 \\
\hline & $\begin{array}{l}7447 \text { participants (aged } 55-80 \\
\text { years) }\end{array}$ & $\begin{array}{l}\text { Plasma metabolites from choline pathway are associated with an } \\
\text { increased risk of CVD }\end{array}$ & Guasch-Ferre et al., 2017 \\
\hline & 4007 participants & $\begin{array}{l}\text { Increased TMAO levels are associated with an increased risk of } \\
\text { cardiovascular }\end{array}$ & Tang et al., 2013 \\
\hline & $\begin{array}{l}13,355 \text { male and } 15,724 \\
\text { female subjects }\end{array}$ & Choline and betaine intakes are not associated with CVD mortality risk & Nagata et al., 2015 \\
\hline & 14,430 middle-aged subjects & $\begin{array}{l}\text { No association exists between dietary choline intake and incident } \\
\text { coronary heart disease }\end{array}$ & Bidulescu et al., 2007 \\
\hline & 18 healthy participants & $\begin{array}{l}\text { Gut microbe-generated TMAO from dietary choline is prothrombotic in } \\
\text { subjects }\end{array}$ & Zhu et al., 2017 \\
\hline \multirow[t]{10}{*}{ Bile acids } & ApoE-/- and LDLR-/- mice & $\begin{array}{l}\text { Dual activation of the bile acid nuclear receptor FXR and } \\
\text { G-protein-coupled receptor TGR5 protects mice against atherosclerosis }\end{array}$ & Miyazaki-Anzai et al., 2014 \\
\hline & Germ-free (GF) mice & $\begin{array}{l}\text { Gut microbiota inhibits bile acid synthesis in the liver by alleviating FXR } \\
\text { inhibition }\end{array}$ & Sayin et al., 2013 \\
\hline & FXR-deficient $(-/-)$ mouse & $\begin{array}{l}\text { The function of FXR is associated with the potential to be } \\
\text { pro-atherogenic }\end{array}$ & (Lambert et al., 2003) \\
\hline & FXR-/- ApoE-/- mice & $\begin{array}{l}\text { Loss of FXR function is associated with more extensive aortic plaque } \\
\text { formation in atherosclerotic disease }\end{array}$ & Hanniman et al., 2005 \\
\hline & LDLR-/- mice & FXR deficiency causes reduced atherosclerosis & Zhang et al., 2006 \\
\hline & Fxr-/- Ldlr-/- (DKO) mice & Activation of FXR protects against atherosclerosis in mice & Hartman et al., 2009 \\
\hline & $\begin{array}{l}\text { Ldlr(-/-)Tgr5(-/-) and } \\
\text { Ldlr(-/-)Tgr5(+/+) mice }\end{array}$ & $\begin{array}{l}\text { TGR5 activation inhibits atherosclerosis by reducing macrophage } \\
\text { inflammation and lipid loading }\end{array}$ & Pols et al., 2011 \\
\hline & $\operatorname{PXR}(-/-)$ apoE $(-/-)$ mice & Deficiency of PXR attenuates atherosclerosis development & Sui et al., 2011 \\
\hline & ApoE(-/-) mice & Activation of PXR accelerates atherosclerosis development & Zhou et al., 2009 \\
\hline & LDLR-/- VDR-/- mice & $\begin{array}{l}\text { Macrophage VDR signaling inhibits atherosclerosis in part by } \\
\text { suppressing the local renin-angiotensin system }\end{array}$ & Szeto et al., 2012 \\
\hline \multirow[t]{4}{*}{ SCFAs } & 205 women & $\begin{array}{l}\text { Blood pressure is associated with alterations in gut microbiota and } \\
\text { production of butyrate }\end{array}$ & Gomez-Arango et al., 2016 \\
\hline & Hypertensive mice & $\begin{array}{l}\text { Acetate supplementation changes the development of hypertension } \\
\text { and heart failure }\end{array}$ & Marques et al., 2017 \\
\hline & Olfr78-/- mice & $\begin{array}{l}\text { SCFAs produced by the gut microbiota modulate blood pressure via } \\
\text { Olfr78 and Gpr } 41\end{array}$ & Pluznick et al., 2013 \\
\hline & Gpr41 knockout mice & Microbial SCFAs lower blood pressure via endothelial GPR41 & Natarajan et al., 2016 \\
\hline
\end{tabular}

SCFAs, short-chain fatty acids; TMAO, trimethylamine N-oxide; BAs, bile acids; Gpr41, G-protein-coupled receptor 41; Olfr78, olfactory receptor 78; FMO3, flavin monooxygenase 3; CD36, the monocyte differentiation antigen; FXR, farnesoid X receptor; ABCA1, ATP-binding membrane cassette transporter A1; LDL-R, lipoprotein receptor; TGR5, G-protein-coupled bile acid receptor; S1PR2, sphingosine-1-phosphate receptor-2; ApoE-/-, apolipoprotein E-deficient. 
shown that an inulin-type fructans (ITFs) supplement improved endothelial function in $\mathrm{ApoE}^{-/-}$mice, while administration of ITFs promoted the production of butyrate and resulted in atheroprotective effects(Watzl et al., 2005; Catry et al., 2018). A previous investigation reported that long-chain inulin could inhibit the formation of atherosclerotic plaque in $\mathrm{ApoE}^{-/-}$ mice, an effect that may be associated with alterations in lipid metabolism (Rault-Nania et al., 2006). In a randomized, singleblind, controlled crossover clinical trial, consumption of $\beta$-glucan altered the composition of gut microbiota, an effect associated with a reduction of CVD risk markers. Additionally, mannan oligosaccharide (MOS) is another type of prebiotic. In a recent study, a MOS supplement modulated the composition of gut microbiota, lowered plasma cholesterol levels, and improved atherosclerotic plaques in high cholesterol diet-fed mice (Hoving et al., 2018).

In addition to probiotic and prebiotic, some natural active ingredients from herbs also have protective or therapeutic actions on CVD by modulating the gut microbiota. For example, berberine is a well-studied herbal-derived chemical with effective activity against atherosclerosis. It was found that the antiatherosclerotic effect of berberine was associated with the stimulation of Akkermansia in $\mathrm{ApoE}^{-/-}$mice (Zhu et al., 2018). Another example is resveratrol that may have protective effect against several cardiovascular risk factors such as hypercholesterol and TMAO by modulating the gut microbiota and expression of genes involved in maintaining the integrity of the gut barrier (Bird et al., 2017). Moreover, resveratrol was found to attenuate TMAO-induced atherosclerosis by decreasing gut microbiota-mediated TMAO synthesis and increasing BA metabolism (Chen et al., 2016).

Fecal microbiota transplantation (FMT) is a promising method of introducing "healthy" bacteria from healthy subjects into the gastrointestinal tract of patients with dysfunctional guts, which has received much attention in recent years (Colman and Rubin, 2014). In one study, the insulin sensitivity of recipients was significantly enhanced after 6 weeks transfer of microbiota from lean normal donors to male recipients with metabolic syndrome. FMT increased the abundance of butyrate-producing bacteria suggesting that FMT is a potential strategy for CVD therapy (Vrieze et al., 2012). Nevertheless, the use of FMT is also limited in the clinic due to the possible risk of transferring endotoxins or infectious diseases to recipients (De Leon et al., 2013).

Although gut microbiota-targeted therapy to treat CVD is promising in the context of increasing positive experimental and clinical evidence, discrepant results have also been reported in both experimental and clinical studies. For instance, recently, scientists evaluated the effects of probiotic intervention on plasma TMAO levels in CKD patients, but there no significant change was observed after 3 months supplementation

\section{REFERENCES}

Akira, S., and Takeda, K. (2004). Toll-like receptor signalling. Nat. Rev. Immunol. 4, 499-511. doi: 10.1038/nri1391

Akira, S., Uematsu, S., and Takeuchi, O. (2006). Pathogen recognition and innate immunity. Cell 124, 783-801. doi: 10.1016/j.cell.2006.02.015
(Borges et al., 2018). Similarly, FMT from vegans resulted in a slight alteration in the composition of the gut microbiota, but no improvement in TMAO production or vascular inflammation (Smits et al., 2018).

\section{CONCLUSION}

Although many types of medicines are available in the clinic to treat CVD, currently, it is still the leading cause of death worldwide. In recent years, increasing evidence has suggested an important role for gut microbiota in the development of both metabolic diseases and CVD. The findings have shed light on the great potential of targeting the gut microbiota to aid the elucidation of the fundamental mechanisms underlying disease and/or to uncover novel preventative or therapeutic regimes. Currently, most of the research efforts have focused on paid on establishing the relationship between gut dysbiosis and the development of CVD. Although much progress has been made, there is some way to go before the unequivocal establishment of gut microbiota-targeted therapy for CVD in the clinic.

Given the experimental and clinical advances with regard to the mechanisms of gut microbiota in the pathogenesis of CVD, there is great promise of finding new approaches to treat CVD by using gut microbial metabolites such as SCFAs and some types of BAs, or blocking the production of detrimental microbial metabolites such as TMAO with inhibitors. In addition, methods to alter the gut microbial composition with probiotic, prebiotic, natural components, and FMT should be further explored. In the future well-designed large-scale clinical studies will be needed to validate experimental and other small-scale preliminary clinical data. The integration of omics approaches (metabolomics, metagenomics, and metatranscriptomics) may be of critical significance to explore the exact roles of identified gut bacteria in the pathogenesis of many diseases.

\section{AUTHOR CONTRIBUTIONS}

JM drafted the manuscript. HL revised the manuscript.

\section{FUNDING}

This work was funded by the National Key Research and Development Program of China (No. 2017YFC1700200), National Natural Science Foundation of China (No. 81673662), The Program for Professor of Special Appointment (Eastern Scholar), and Shuguang Scholar (16SG36) at Shanghai Institutions of Higher Learning from Shanghai Municipal Education Commission.

Anbazhagan, A. N., Priyamvada, S., and Priyadarshini, M. (2017) Gut microbiota in vascular disease: therapeutic target? Curr. Vasc. Pharmacol. 15, 291-295. doi: 10.2174/15701611156661701050 95834

Andraws, R., Berger, J. S., and Brown, D. L. (2005). Effects of antibiotic therapy on outcomes of patients with coronary artery disease: a meta-analysis of 
randomized controlled trials. JAMA 293, 2641-2647. doi: 10.1001/jama.293.21. 2641

Barton, G. M., and Kagan, J. C. (2009). A cell biological view of Toll-like receptor function: regulation through compartmentalization. Nat. Rev. Immunol. 9, 535-542. doi: 10.1038/nri2587

Bennett, B. J., de Aguiar Vallim, T. Q., Wang, Z., Shih, D. M., Meng, Y., Gregory, J., et al. (2013). Trimethylamine-N-oxide, a metabolite associated with atherosclerosis, exhibits complex genetic and dietary regulation. Cell Metab. 17, 49-60. doi: 10.1016/j.cmet.2012.12.011

Bergeron, N., Williams, P. T., Lamendella, R., Faghihnia, N., Grube, A., Li, X., et al. (2016). Diets high in resistant starch increase plasma levels of trimethylamine$\mathrm{N}$-oxide, a gut microbiome metabolite associated with CVD risk. Br. J. Nutr. 116, 2020-2029. doi: 10.1017/s0007114516004165

Bidulescu, A., Chambless, L. E., Siega-Riz, A. M., Zeisel, S. H., and Heiss, G. (2007). Usual choline and betaine dietary intake and incident coronary heart disease: the Atherosclerosis Risk in Communities (ARIC) study. BMC Cardiovasc. Disord. 7:20. doi: 10.1186/1471-2261-7-20

Bird, J. K., Raederstorff, D., Weber, P., and Steinert, R. E. (2017). Cardiovascular and antiobesity effects of resveratrol mediated through the gut microbiota. $A d v$. Nutr. 8, 839-849. doi: 10.3945/an.117.016568

Bjorkbacka, H., Kunjathoor, V. V., Moore, K. J., Koehn, S., Ordija, C. M., Lee, M. A., et al. (2004). Reduced atherosclerosis in MyD88-null mice links elevated serum cholesterol levels to activation of innate immunity signaling pathways. Nat. Med. 10, 416-421. doi: 10.1038/nm1008

Borges, N. A., Stenvinkel, P., Bergman, P., Qureshi, A. R., Lindholm, B., Moraes, C., et al. (2018). Effects of probiotic supplementation on trimethylamine-N-Oxide plasma levels in hemodialysis patients: a pilot study. Probiotics Antimicrob Proteins. [Epub ahead of print]. doi: 10.1007/s12602-018-9411-1

Boulanger, C., and Luscher, T. F. (1990). Release of endothelin from the porcine aorta, inhibition by endothelium-derived nitric oxide. J. Clin. Invest. 85, 587590. doi: 10.1172/jci114477

Brown, J. M., and Hazen, S. L. (2015). The gut microbial endocrine organ: bacterially derived signals driving cardiometabolic diseases. Annu. Rev. Med. 66, 343-359. doi: 10.1146/annurev-med-060513-093205

Brown, J. M., and Hazen, S. L. (2018). Microbial modulation of cardiovascular disease. Nat. Rev. Microbiol. 16, 171-181. doi: 10.1038/nrmicro.2017.149

Caligiuri, G., Rottenberg, M., Nicoletti, A., Wigzell, H., and Hansson, G. K. (2001). Chlamydia pneumoniae infection does not induce or modify atherosclerosis in mice. Circulation 103, 2834-2838. doi: 10.1161/01.CIR.103.23.2834

Canfora, E. E., Jocken, J. W., and Blaak, E. E. (2015). Short-chain fatty acids in control of body weight and insulin sensitivity. Nat. Rev. Endocrinol. 11, 577-591. doi: 10.1038/nrendo.2015.128

Cani, P. D., Amar, J., Iglesias, M. A., Poggi, M., Knauf, C., Bastelica, D., et al. (2007). Metabolic endotoxemia initiates obesity and insulin resistance. Diabetes Metab. Res. Rev. 56:1761.

Cani, P. D., Bibiloni, R., Knauf, C., Waget, A., Neyrinck, A. M., Delzenne, N. M., et al. (2008). Changes in gut microbiota control metabolic endotoxemiainduced inflammation in high-fat diet-induced obesity and diabetes in mice. Diabetes Metab. Res. Rev. 57, 1470-1481. doi: 10.2337/db07-1403

Catry, E., Bindels, L. B., Tailleux, A., Lestavel, S., Neyrinck, A. M., Goossens, J. F., et al. (2018). Targeting the gut microbiota with inulin-type fructans: preclinical demonstration of a novel approach in the management of endothelial dysfunction. Gut 67, 271-283. doi: 10.1136/gutjnl-2016-3 13316

Chacon, M. R., Lozano-Bartolome, J., Portero-Otin, M., Rodriguez, M. M., Xifra, G., Puig, J., et al. (2017). The gut mycobiome composition is linked to carotid atherosclerosis. Benef. Microbes 9, 1-14. doi: 10.3920/bm2017. 0029

Chawla, A., Nguyen, K. D., and Goh, Y. P. (2011). Macrophage-mediated inflammation in metabolic disease. Nat. Rev. Immunol. 11, 738-749. doi: 10. 1038/nri3071

Chen, K., Zheng, X., Feng, M., Li, D., and Zhang, H. (2017). Gut microbiotadependent metabolite trimethylamine n-oxide contributes to cardiac dysfunction in western diet-induced obese mice. Front. Physiol. 8:139. doi: 10.3389/fphys.2017.00139

Chen, W. Y., Wang, M., Zhang, J., Barve, S. S., McClain, C. J., and Joshi-Barve, S. (2017). Acrolein disrupts tight junction proteins and causes endoplasmic reticulum stress-mediated epithelial cell death leading to intestinal barrier dysfunction and permeability. Am. J. Pathol. 187, 2686-2697. doi: 10.1016/j. ajpath.2017.08.015

Chen, M. L., Yi, L., Zhang, Y., Zhou, X., Ran, L., Yang, J., et al. (2016). Resveratrol attenuates trimethylamine-N-Oxide (TMAO)-induced atherosclerosis by regulating TMAO synthesis and bile acid metabolism via remodeling of the gut microbiota. MBio 7:e02210-15. doi: 10.1128/mBio.02210-15

Collins, H. L., Drazul-Schrader, D., Sulpizio, A. C., Koster, P. D., Williamson, Y., Adelman, S. J., et al. (2016). L-Carnitine intake and high trimethylamine $\mathrm{N}$-oxide plasma levels correlate with low aortic lesions in ApoE(-/-) transgenic mice expressing CETP. Atherosclerosis 244, 29-37. doi: 10.1016/j. atherosclerosis.2015.10.108

Colman, R. J., and Rubin, D. T. (2014). Fecal microbiota transplantation as therapy for inflammatory bowel disease: a systematic review and meta-analysis. J. Crohns Colitis 8, 1569-1581. doi: 10.1016/j.crohns.2014.08.006

Costabile, A., Buttarazzi, I., Kolida, S., Quercia, S., Baldini, J., Swann, J. R., et al. (2017). An in vivo assessment of the cholesterol-lowering efficacy of Lactobacillus plantarum ECGC 13110402 in normal to mildly hypercholesterolaemic adults. PLoS One 12:e187964. doi: 10.1371/journal. pone.0187964

Daliri, E. B., Lee, B. H., and Oh, D. H. (2017). Current perspectives on antihypertensive probiotics. Probiot. Antimicrob. Proteins 9, 91-101. doi: 10. 1007/s12602-016-9241-y

Dalmeijer, G. W., Olthof, M. R., Verhoef, P., Bots, M. L., and van der Schouw, Y. T. (2008). Prospective study on dietary intakes of folate, betaine, and choline and cardiovascular disease risk in women. Eur. J. Clin. Nutr. 62, 386-394. doi: $10.1038 /$ sj.ejcn. 1602725

Dawson, P. A., and Karpen, S. J. (2015). Intestinal transport and metabolism of bile acids. J. Lipid Res. 56, 1085-1099. doi: 10.1194/jlr.R054114

De Leon, L. M., Watson, J. B., and Kelly, C. R. (2013). Transient flare of ulcerative colitis after fecal microbiota transplantation for recurrent Clostridium difficile infection. Clin. Gastroenterol. Hepatol. 11, 1036-1038. doi: 10.1016/j.cgh.2013. 04.045

Desai, M. S., Seekatz, A. M., Koropatkin, N. M., Kamada, N., Hickey, C. A., Wolter, M., et al. (2016). A dietary fiber-deprived gut microbiota degrades the colonic mucus barrier and enhances pathogen susceptibility. Cell 167, 1339.e1321-1353.e1321. doi: 10.1016/j.cell.2016.10.043

Ding, S., Chi, M. M., Scull, B. P., Rigby, R., Schwerbrock, N. M. J., Magness, S., et al. (2010). High-fat diet: bacteria interactions promote intestinal inflammation which precedes and correlates with obesity and insulin resistance in mouse. PLoS One 5:e12191. doi: 10.1371/journal.pone.0012191

Ding, Y., Subramanian, S., Montes, V. N., Goodspeed, L., Wang, S., Han, C., et al. (2012). Toll-like receptor 4 deficiency decreases atherosclerosis but does not protect against inflammation in obese low-density lipoprotein receptordeficient mice. Arterioscler. Thromb. Vasc. Biol. 32, 1596-1604. doi: 10.1161/ atvbaha.112.249847

Drosos, I., Tavridou, A., and Kolios, G. (2015). New aspects on the metabolic role of intestinal microbiota in the development of atherosclerosis. Metabolism 64, 476-481. doi: 10.1016/j.metabol.2015.01.007

Duncan, S. H., Barcenilla, A., Stewart, C. S., Pryde, S. E., and Flint, H. J. (2002). Acetate utilization and butyryl coenzyme A (CoA):acetate-CoA transferase in butyrate-producing bacteria from the human large intestine. Appl. Environ. Microbiol. 68, 5186-5190. doi: 10.1128/AEM.68.10.5186-5190.2002

Edfeldt, K., Swedenborg, J., Hansson, G. K., and Yan, Z. Q. (2002). Expression of toll-like receptors in human atherosclerotic lesions: a possible pathway for plaque activation. Circulation 105, 1158-1161.

El Kaoutari, A., Armougom, F., Gordon, J. I., Raoult, D., and Henrissat, B. (2013). The abundance and variety of carbohydrate-active enzymes in the human gut microbiota. Nat. Rev. Microbiol. 11, 497-504. doi: 10.1038/nrmicro 3050

Emoto, T., Yamashita, T., Kobayashi, T., Sasaki, N., Hirota, Y., Hayashi, T., et al. (2017). Characterization of gut microbiota profiles in coronary artery disease patients using data mining analysis of terminal restriction fragment length polymorphism: gut microbiota could be a diagnostic marker of coronary artery disease. Heart Vessels 32, 39-46. doi: 10.1007/s00380-0160841-y

Ettinger, G., MacDonald, K., Reid, G., and Burton, J. P. (2014). The influence of the human microbiome and probiotics on cardiovascular health. Gut Microbes 5, 719-728. doi: 10.4161/19490976.2014.983775 
Fuentes, M. C., Lajo, T., Carrion, J. M., and Cune, J. (2013). Cholesterollowering efficacy of Lactobacillus plantarum CECT 7527, 7528 and 7529 in hypercholesterolaemic adults. Br. J. Nutr. 109, 1866-1872. doi: 10.1017/ s000711451200373x

Furusawa, Y., Obata, Y., Fukuda, S., Endo, T. A., Nakato, G., Takahashi, D., et al. (2013). Commensal microbe-derived butyrate induces the differentiation of colonic regulatory T cells. Nature 504, 446-450. doi: 10.1038/nature12721

Gibson, G. R., and Roberfroid, M. B. (1995). Dietary modulation of the human colonic microbiota: introducing the concept of prebiotics. J. Nutr. 125, 14011412.

Gomez-Arango, L. F., Barrett, H. L., McIntyre, H. D., Callaway, L. K., Morrison, M., and Dekker Nitert, M. (2016). Increased systolic and diastolic blood pressure is associated with altered gut microbiota composition and butyrate production in early pregnancy. Hypertension 68, 974-981. doi: 10.1161/hypertensionaha.116. 07910

Gomez-Guzman, M., Toral, M., Romero, M., Jimenez, R., Galindo, P., Sanchez, M., et al. (2015). Antihypertensive effects of probiotics Lactobacillus strains in spontaneously hypertensive rats. Mol. Nutr. Food Res. 59, 2326-2336. doi: 10. 1002/mnfr.201500290

Gopalakrishnan, V., Helmink, B. A., Spencer, C. N., Reuben, A., and Wargo, J. A. (2018). The influence of the gut microbiome on cancer, immunity, and cancer immunotherapy. Cancer Cell 33, 570-580. doi: 10.1016/j.ccell.2018.03.015

Gregory, J. C., Buffa, J. A., Org, E., Wang, Z., Levison, B. S., Zhu, W., et al. (2015). Transmission of atherosclerosis susceptibility with gut microbial transplantation. J. Biol. Chem. 290, 5647-5660. doi: 10.1074/jbc.M114.618249

Guasch-Ferre, M., Hu, F. B., Ruiz-Canela, M., Bullo, M., Toledo, E., Wang, D. D., et al. (2017). Plasma metabolites from choline pathway and risk of cardiovascular disease in the PREDIMED (Prevention With Mediterranean Diet) Study. J. Am. Heart Assoc. 6:e006524. doi: 10.1161/jaha.117.006524

Gui, T., Shimokado, A., Sun, Y., Akasaka, T., and Muragaki, Y. (2012). Diverse roles of macrophages in atherosclerosis: from inflammatory biology to biomarker discovery. Mediat. Inflamm. 2012:693083. doi: 10.1155/2012/693083

Guzzo, C., Ayer, A., Basta, S., Banfield, B. W., and Gee, K. (2012). IL-27 enhances LPS-induced proinflammatory cytokine production via upregulation of TLR4 expression and signaling in human monocytes. J. Immunol. 188, 864-873. doi: 10.4049/jimmunol.1101912

Hanniman, E. A., Lambert, G., McCarthy, T. C., and Sinal, C. J. (2005). Loss of functional farnesoid $\mathrm{X}$ receptor increases atherosclerotic lesions in apolipoprotein E-deficient mice. J. Lipid Res. 46, 2595-2604. doi: 10.1194/jlr. M500390-JLR200

Hansen, T. H., Gobel, R. J., Hansen, T., and Pedersen, O. (2015). The gut microbiome in cardio-metabolic health. Genome Med. 7:33. doi: 10.1186/ s13073-015-0157-z

Hansson, G. K., Robertson, A. K., and Soderberg-Naucler, C. (2006). Inflammation and atherosclerosis. Annu. Rev. Pathol. 1, 297-329. doi: 10.1146/annurev. pathol.1.110304.100100

Harris, K., Kassis, A., Major, G., and Chou, C. J. (2012). Is the gut microbiota a new factor contributing to obesity and its metabolic disorders? J. Obes. 2012:879151. doi: 10.1155/2012/879151

Hartman, H. B., Gardell, S. J., Petucci, C. J., Wang, S., Krueger, J. A., and Evans, M. J. (2009). Activation of farnesoid X receptor prevents atherosclerotic lesion formation in LDLR-/- and apoE-/- mice. J. Lipid Res. 50, 1090-1100. doi: 10. 1194/jlr.M800619-JLR200

He, M., and Shi, B. (2017). Gut microbiota as a potential target of metabolic syndrome: the role of probiotics and prebiotics. Cell Biosci. 7:54. doi: 10.1186/ s13578-017-0183-1

Henao-Mejia, J., Elinav, E., Jin, C., Hao, L., Mehal, W. Z., Strowig, T., et al. (2012). Inflammasome-mediated dysbiosis regulates progression of NAFLD and obesity. Nature 482, 179-185. doi: 10.1038/nature10809

Honour, J. (1982). The possible involvement of intestinal bacteria in steroidal hypertension. Endocrinology 110, 285-287. doi: 10.1210/endo-110-1-285

Hoving, L. R., Katiraei, S., Heijink, M., Pronk, A., van der Wee-Pals, L., Streefland, T., et al. (2018). Dietary mannan oligosaccharides modulate gut microbiota, increase fecal bile acid excretion, and decrease plasma cholesterol and atherosclerosis development. Mol. Nutr. Food Res. 62:e1700942. doi: 10. 1002/mnfr.201700942

Jie, Z., Xia, H., Zhong, S. L., Feng, Q., Li, S., Liang, S., et al. (2017). The gut microbiome in atherosclerotic cardiovascular disease. Nat. Commun. 8:845. doi: 10.1038/s41467-017-00900-1
Jones, M. L., Martoni, C. J., Ganopolsky, J. G., Labbe, A., and Prakash, S. (2014). The human microbiome and bile acid metabolism: dysbiosis, dysmetabolism, disease and intervention. Exp. Opin. Biol. Ther. 14, 467-482. doi: 10.1517/ 14712598.2014 .880420

Jones, M. L., Martoni, C. J., Parent, M., and Prakash, S. (2012a). Cholesterollowering efficacy of a microencapsulated bile salt hydrolase-active Lactobacillus reuteri NCIMB 30242 yoghurt formulation in hypercholesterolaemic adults. $B r$. J. Nutr. 107, 1505-1513. doi: 10.1017/s0007114511004703

Jones, M. L., Martoni, C. J., and Prakash, S. (2012b). Cholesterol lowering and inhibition of sterol absorption by Lactobacillus reuteri NCIMB 30242: a randomized controlled trial. Eur. J. Clin. Nutr. 66, 1234-1241. doi: 10.1038/ejcn. 2012.126

Jonsson, A. L., and Backhed, F. (2017). Role of gut microbiota in atherosclerosis. Nat. Rev. Cardiol. 14, 79-87. doi: 10.1038/nrcardio.2016.183

Joyce, S. A., and Gahan, C. G. (2017). Disease-associated changes in bile acid profiles and links to altered gut microbiota. Dig. Dis. 35, 169-177. doi: 10.1159/ 000450907

Kailasapathy, K., and Chin, J. (2000). Survival and therapeutic potential of probiotic organisms with reference to Lactobacillus acidophilus and Bifidobacterium spp. Immunol. Cell Biol. 78, 80-88. doi: 10.1046/j.1440-1711. 2000.00886.x

Kamada, N., Seo, S. U., Chen, G. Y., and Nunez, G. (2013). Role of the gut microbiota in immunity and inflammatory disease. Nat. Rev. Immunol. 13, 321-335. doi: 10.1038/nri3430

Kamo, T., Akazawa, H., Suda, W., Saga-Kamo, A., Shimizu, Y., Yagi, H., et al. (2017). Dysbiosis and compositional alterations with aging in the gut microbiota of patients with heart failure. PLoS One 12:e0174099. doi: 10.1371/ journal.pone.0174099

Kanno, S., Nishio, H., Tanaka, T., Motomura, Y., Murata, K., Ihara, K., et al. (2015). Activation of an innate immune receptor, Nod1, accelerates atherogenesis in Apoe-/- mice. J. Immunol. 194, 773-780. doi: 10.4049/jimmunol.1302841

Karbach, S. H., Schonfelder, T., Brandao, I., Wilms, E., Hormann, N., Jackel, S., et al. (2016). Gut microbiota promote angiotensin ii-induced arterial hypertension and vascular dysfunction. J. Am. Heart Assoc. 5:e003698. doi: 10.1161/jaha.116. 003698

Karlsson, F. H., Fak, F., Nookaew, I., Tremaroli, V., Fagerberg, B., Petranovic, D., et al. (2012). Symptomatic atherosclerosis is associated with an altered gut metagenome. Nat. Commun. 3:1245. doi: 10.1038/ncomms2266

Kasahara, K., Tanoue, T., Yamashita, T., Yodoi, K., Matsumoto, T., Emoto, T., et al. (2017). Commensal bacteria at the crossroad between cholesterol homeostasis and chronic inflammation in atherosclerosis. J. Lipid Res. 58, 519-528. doi: 10.1194/jlr.M072165

Khan, M. T., Nieuwdorp, M., and Backhed, F. (2014). Microbial modulation of insulin sensitivity. Cell Metab. 20, 753-760. doi: 10.1016/j.cmet.2014. 07.006

Kholy, K. E., Genco, R. J., and Van Dyke, T. E. (2015). Oral infections and cardiovascular disease. Trends Endocrinol. Metab. 26, 315-321. doi: 10.1016/ j.tem.2015.03.001

Klaassen, C. D., and Cui, J. Y. (2015). Review: mechanisms of how the intestinal microbiota alters the effects of drugs and bile acids. Drug Metab. Dispos. 43, 1505-1521. doi: 10.1124/dmd.115.065698

Kobayashi, K. S., Chamaillard, M., Ogura, Y., Henegariu, O., Inohara, N., Nunez, G., et al. (2005). Nod2-dependent regulation of innate and adaptive immunity in the intestinal tract. Science 307, 731-734. doi: 10.1126/science. 1104911

Koeth, R. A., Levison, B. S., Culley, M. K., Buffa, J. A., Wang, Z., Gregory, J. C., et al. (2014). gamma-butyrobetaine is a proatherogenic intermediate in gut microbial metabolism of L-carnitine to TMAO. Cell Metab. 20, 799-812. doi: 10.1016/j.cmet.2014.10.006

Koeth, R. A., Wang, Z., Levison, B. S., Buffa, J. A., Org, E., Sheehy, B. T., et al. (2013). Intestinal microbiota metabolism of L-carnitine, a nutrient in red meat, promotes atherosclerosis. Nat. Med. 19, 576-585. doi: 10.1038/nm. 3145

Koh, A., De Vadder, F., Kovatcheva-Datchary, P., and Backhed, F. (2016). From dietary fiber to host physiology: short-chain fatty acids as key bacterial metabolites. Cell 165, 1332-1345. doi: 10.1016/j.cell.2016.05.041

Koopen, A. M., Groen, A. K., and Nieuwdorp, M. (2016). Human microbiome as therapeutic intervention target to reduce cardiovascular disease risk. Curr. Opin. Lipidol. 27, 615-622. doi: 10.1097/mol.0000000000000357 
Kuipers, F., Bloks, V. W., and Groen, A. K. (2014). Beyond intestinal soap-bile acids in metabolic control. Nat. Rev. Endocrinol. 10, 488-498. doi: 10.1038/ nrendo. 2014.60

Laman, J. D., Schoneveld, A. H., Moll, F. L., van Meurs, M., and Pasterkamp, G. (2002). Significance of peptidoglycan, a proinflammatory bacterial antigen in atherosclerotic arteries and its association with vulnerable plaques. Am. J. Cardiol. 90, 119-123. doi: 10.1016/S0002-9149(02)02432-3

Lambert, G., Amar, M. J., Guo, G., Brewer, H. B. Jr., Gonzalez, F. J., et al. (2003). The farnesoid X-receptor is an essential regulator of cholesterol homeostasis. J. Biol. Chem. 278, 2563-2570. doi: 10.1074/jbc.M209525200

Lau, K., Srivatsav, V., Rizwan, A., Nashed, A., Liu, R., Shen, R., et al. (2017). Bridging the gap between gut microbial dysbiosis and cardiovascular diseases. Nutrients 9:E859. doi: 10.3390/nu9080859

Lefebvre, P., Cariou, B., Lien, F., Kuipers, F., and Staels, B. (2009). Role of bile acids and bile acid receptors in metabolic regulation. Physiol. Rev. 89, 147-191. doi: 10.1152/physrev.00010.2008

Lepercq, P., Gerard, P., Beguet, F., Raibaud, P., Grill, J. P., Relano, P., et al. (2004). Epimerization of chenodeoxycholic acid to ursodeoxycholic acid by Clostridium baratii isolated from human feces. FEMS Microbiol. Lett. 235, 65-72. doi: 10. 1016/j.femsle.2004.04.011

Levi, M. (2016). Role of bile acid-regulated nuclear receptor FXR and G proteincoupled receptor TGR5 in regulation of cardiorenal syndrome (cardiovascular disease and chronic kidney disease). Hypertension 67, 1080-1084. doi: 10.1161/ hypertensionaha.115.06417

Ley, R. E., Turnbaugh, P. J., Klein, S., and Gordon, J. I. (2006). Microbial ecology: human gut microbes associated with obesity. Nature 444, 1022-1023. doi: 10 . $1038 / 4441022 \mathrm{a}$

Li, J., Lin, S., Vanhoutte, P. M., Woo, C. W., and Xu, A. (2016). Akkermansia muciniphila protects against atherosclerosis by preventing metabolic endotoxemia-induced inflammation in apoe-/- mice. Circulation 133, 2434-2446. doi: 10.1161/circulationaha.115.019645

Li, T., and Chiang, J. Y. (2015). Bile acids as metabolic regulators. Curr. Opin. Gastroenterol. 31, 159-165. doi: 10.1097/mog.0000000000000156

Li, X., Shimizu, Y., and Kimura, I. (2017). Gut microbial metabolite short-chain fatty acids and obesity. Biosci. Microbiota Food Health 36, 135-140. doi: 10. 12938/bmfh.17-010

Libby, P. (2002). Inflammation in atherosclerosis. Nature 420, 868-874. doi: 10. 1038 /nature 01323

Louis, P., and Flint, H. J. (2017). Formation of propionate and butyrate by the human colonic microbiota. Environ. Microbiol. 19, 29-41. doi: 10.1111/14622920.13589

Luscher, T. F., and Barton, M. (1997). Biology of the endothelium. Clin. Cardiol. 20(11 Suppl. 2), II-3-10.

Ma, F. X., Zhou, B., Chen, Z., Ren, Q., Lu, S. H., Sawamura, T., et al. (2006). Oxidized low density lipoprotein impairs endothelial progenitor cells by regulation of endothelial nitric oxide synthase. J. Lipid Res. 47, 1227-1237. doi: 10.1194/jlr.M500507-JLR200

Ma, G., Pan, B., Chen, Y., Guo, C., Zhao, M., Zheng, L., et al. (2017). Trimethylamine N-oxide in atherogenesis: impairing endothelial self-repair capacity and enhancing monocyte adhesion. Biosci. Rep. 37:BSR20160244. doi: 10.1042/bsr20160244

Makishima, M., Lu, T. T., Xie, W., Whitfield, G. K., Domoto, H., Evans, R. M., et al. (2002). Vitamin D receptor as an intestinal bile acid sensor. Science 296, 1313-1316. doi: 10.1126/science. 1070477

Makishima, M., Okamoto, A. Y., Repa, J. J., Tu, H., Learned, R. M., Luk, A., et al. (1999). Identification of a nuclear receptor for bile acids. Science 284, 1362-1365. doi: 10.1126/science.284.5418.1362

Marques, F. Z., Nelson, E., Chu, P. Y., Horlock, D., Fiedler, A., Ziemann, M., et al. (2017). High-fiber diet and acetate supplementation change the gut microbiota and prevent the development of hypertension and heart failure in hypertensive mice. Circulation 135, 964-977. doi: 10.1161/circulationaha.116.024545

McIntyre, C. W., Harrison, L. E., Eldehni, M. T., Jefferies, H. J., Szeto, C. C., John, S. G., et al. (2011). Circulating endotoxemia: a novel factor in systemic inflammation and cardiovascular disease in chronic kidney disease. Clin. J. Am. Soc. Nephrol. 6, 133-141. doi: 10.2215/cjn.04610510

Mencarelli, A., Renga, B., Distrutti, E., and Fiorucci, S. (2009). Antiatherosclerotic effect of farnesoid X receptor. Am. J. Physiol. Heart Circ. Physiol. 296, H272H281. doi: 10.1152/ajpheart.01075.2008
Meyer, K. A., Benton, T. Z., Bennett, B. J., Jacobs, D. R. Jr., Lloyd-Jones, D. M., et al. (2016). Microbiota-dependent metabolite trimethylamine n-oxide and coronary artery calcium in the coronary artery risk development in young adults study (CARDIA). J. Am. Heart Assoc. 5:e03970. doi: 10.1161/jaha.116. 003970

Miao, J., Ling, A. V., Manthena, P. V., Gearing, M. E., Graham, M. J., Crooke, R. M., et al. (2015). Flavin-containing monooxygenase 3 as a potential player in diabetes-associated atherosclerosis. Nat. Commun. 6:6498. doi: 10.1038/ ncomms 7498

Midtvedt, T. (1974). Microbial bile acid transformation. Am. J. Clin. Nutr. 27, 1341-1347. doi: 10.1093/ajcn/27.11.1341

Miller, M. A., McTernan, P. G., Harte, A. L., Silva, N. F., Strazzullo, P., Alberti, K. G., et al. (2009). Ethnic and sex differences in circulating endotoxin levels: a novel marker of atherosclerotic and cardiovascular risk in a British multi-ethnic population. Atherosclerosis 203, 494-502. doi: 10.1016/j.atherosclerosis.2008.06. 018

Mitra, S., Drautz-Moses, D. I., Alhede, M., Maw, M. T., Liu, Y., Purbojati, R. W., et al. (2015). In silico analyses of metagenomes from human atherosclerotic plaque samples. Microbiome 3:38. doi: 10.1186/s40168-015-0100-y

Miura, K., and Ohnishi, H. (2014). Role of gut microbiota and Toll-like receptors in nonalcoholic fatty liver disease. World J. Gastroenterol. 20, 7381-7391. doi: 10.3748/wjg.v20.i23.7381

Miyamoto, J., Kasubuchi, M., Nakajima, A., Irie, J., Itoh, H., and Kimura, I. (2016). The role of short-chain fatty acid on blood pressure regulation. Curr. Opin. Nephrol. Hypertens. 25, 379-383. doi: 10.1097/mnh.00000000000 00246

Miyazaki-Anzai, S., Masuda, M., Levi, M., Keenan, A. L., and Miyazaki, M. (2014). Dual activation of the bile acid nuclear receptor FXR and G-protein-coupled receptor TGR5 protects mice against atherosclerosis. PLoS One 9:e108270. doi: 10.1371/journal.pone.0108270

Mouzaki, M., Comelli, E. M., Arendt, B. M., Bonengel, J., Fung, S. K., Fischer, S. E., et al. (2013). Intestinal microbiota in patients with nonalcoholic fatty liver disease. Hepatology 58, 120-127. doi: 10.1002/hep.26319

Mozaffarian, D., Benjamin, E. J., Go, A. S., Arnett, D. K., Blaha, M. J., Cushman, M., et al. (2016). Heart disease and stroke statistics-2016 Update: a report from the american heart association. Circulation 133, e38-e360. doi: 10.1161/cir. 0000000000000350

Munford, R. S. (2016). Endotoxemia-menace, marker, or mistake? J. Leukoc. Biol. 100, 687-698. doi: 10.1189/jlb.3RU0316-151R

Nagata, C., Wada, K., Tamura, T., Konishi, K., Kawachi, T., Tsuji, M., et al. (2015). Choline and betaine intakes are not associated with cardiovascular disease mortality risk in japanese men and women. J. Nutr. 145, 1787-1792. doi: 10.3945/jn.114.209296

Natarajan, N., Hori, D., Flavahan, S., Steppan, J., Flavahan, N. A., Berkowitz, D. E., et al. (2016). Microbial short chain fatty acid metabolites lower blood pressure via endothelial G protein-coupled receptor 41. Physiol. Genomics 48, 826-834. doi: 10.1152/physiolgenomics.00089.2016

Neves, A. L., Coelho, J., Couto, L., Leite-Moreira, A., et al. (2013). Metabolic endotoxemia: a molecular link between obesity and cardiovascular risk. J. Mol. Endocrinol. 51, R51-R64. doi: 10.1530/JME-13-0079

Niebauer, J., Volk, H. D., Kemp, M., Dominguez, M., Schumann, R. R., Rauchhaus, M., et al. (1999). Endotoxin and immune activation in chronic heart failure: a prospective cohort study. Lancet 353, 1838-1842. doi: 10.1016/S01406736(98)09286-1

Packer, C. S., Rice, A. E., Johnson, T. C., Pelaez, N. J., Temm, C. J., Potter, G. V., et al. (2014). Oxidized low density lipoprotein (OX-LDL) induced arterial muscle contraction signaling mechanisms. Open Hyperten. J. 6, 20-26. doi: 10.2174/ 1876526201406010020

Parseus, A., Sommer, N., Sommer, F., Caesar, R., Molinaro, A., Stahlman, M., et al. (2017). Microbiota-induced obesity requires farnesoid X receptor. Gut 66, 429-437. doi: 10.1136/gutjnl-2015-310283

Pedersen, H. K., Gudmundsdottir, V., Nielsen, H. B., Hyotylainen, T., Nielsen, T., Jensen, B. A., et al. (2016). Human gut microbes impact host serum metabolome and insulin sensitivity. Nature 535, 376-381. doi: 10.1038/nature18646

Peluso, I., Morabito, G., Urban, L., Ioannone, F., and Serafini, M. (2012). Oxidative stress in atherosclerosis development: the central role of LDL and oxidative burst. Endocr. Metab. Immune Disord. Drug Targets 12, 351-360. doi: 10.2174/ 187153012803832602 
Philpott, D. J., Sorbara, M. T., Robertson, S. J., Croitoru, K., and Girardin, S. E. (2014). NOD proteins: regulators of inflammation in health and disease. Nat. Rev. Immunol. 14, 9-23. doi: 10.1038/nri3565

Pluznick, J. L. (2013). Renal and cardiovascular sensory receptors and blood pressure regulation. Am. J. Physiol. Renal. Physiol. 305, F439-F444. doi: 10. 1152/ajprenal.00252.2013

Pluznick, J. L., Protzko, R. J., Gevorgyan, H., Peterlin, Z., Sipos, A., Han, J., et al. (2013). Olfactory receptor responding to gut microbiota-derived signals plays a role in renin secretion and blood pressure regulation. Proc. Natl. Acad. Sci. U.S.A. 110, 4410-4415. doi: 10.1073/pnas.1215927110

Pols, T. W., Nomura, M., Harach, T., Lo Sasso, G., Oosterveer, M. H., Thomas, C., et al. (2011). TGR5 activation inhibits atherosclerosis by reducing macrophage inflammation and lipid loading. Cell Metab. 14, 747-757. doi: 10.1016/j.cmet. 2011.11.006

Qin, J., Li, R., Raes, J., Arumugam, M., Burgdorf, K. S., Manichanh, C., et al. (2010). A human gut microbial gene catalogue established by metagenomic sequencing. Nature 464, 59-65. doi: 10.1038/nature08821

Rault-Nania, M. H., Gueux, E., Demougeot, C., Demigne, C., Rock, E., and Mazur, A. (2006). Inulin attenuates atherosclerosis in apolipoprotein E-deficient mice. Br. J. Nutr. 96, 840-844. doi: 10.1017/BJN20061913

Reijnders, D., Goossens, G. H., Hermes, G. D., Neis, E. P., van der Beek, C. M., Most, J., et al. (2016). Effects of gut microbiota manipulation by antibiotics on host metabolism in obese humans: a randomized doubleblind placebo-controlled trial. Cell Metab. 24:341. doi: 10.1016/j.cmet.2016. 07.008

Rey, F. E., Faith, J. J., Bain, J., Muehlbauer, M. J., Stevens, R. D., Newgard, C. B., et al. (2010). Dissecting the in vivo metabolic potential of two human gut acetogens. J. Biol. Chem. 285, 22082-22090. doi: 10.1074/jbc.M110.117713

Ridlon, J. M., Harris, S. C., Bhowmik, S., Kang, D. J., and Hylemon, P. B. (2016). Consequences of bile salt biotransformations by intestinal bacteria. Gut Microbes 7, 22-39. doi: 10.1080/19490976.2015.1127483

Russell, D. W. (2003). The enzymes, regulation, and genetics of bile acid synthesis. Annu. Rev. Biochem. 72, 137-174. doi: 10.1146/annurev.biochem.72.121801. 161712

Sanders, M. E. (2008). Probiotics: definition, sources, selection, and uses. Clin. Infect. Dis. 46 (Suppl 2), S58-S61; discussion S144-151. doi: 10.1086/523341

Santisteban, M. M., Qi, Y., Zubcevic, J., Kim, S., Yang, T., Shenoy, V., et al. (2017). Hypertension-linked pathophysiological alterations in the gut. Circ. Res. 120, 312-323. doi: 10.1161/circresaha.116.309006

Sayin, S. I., Wahlstrom, A., Felin, J., Jantti, S., Marschall, H. U., Bamberg, K., et al. (2013). Gut microbiota regulates bile acid metabolism by reducing the levels of tauro-beta-muricholic acid, a naturally occurring FXR antagonist. Cell Metab. 17, 225-235. doi: 10.1016/j.cmet.2013.01.003

Senthong, V., Li, X. S., Hudec, T., Coughlin, J., Wu, Y., Levison, B., et al. (2016a). Plasma trimethylamine N-Oxide, a gut microbe-generated phosphatidylcholine metabolite, is associated with atherosclerotic burden. J. Am. Coll. Cardiol. 67:2620. doi: 10.1016/j.jacc.2016. 03.546

Senthong, V., Wang, Z., Li, X. S., Fan, Y., Wu, Y., Tang, W. H. W., et al. (2016b). Intestinal microbiota-generated metabolite trimethylamine-N-Oxide and 5year mortality risk in stable coronary artery disease: the contributory role of intestinal microbiota in aCOURAGE-like patient cohort. J. Am. Heart Assoc. 5:e002816. doi: 10.1161/JAHA.115.002816

Shih, D. M., Wang, Z., Lee, R., Meng, Y., Che, N., Charugundla, S., et al. (2015). Flavin containing monooxygenase 3 exerts broad effects on glucose and lipid metabolism and atherosclerosis. J. Lipid Res. 56, 22-37. doi: 10.1194/jlr. M051680

Skoura, A., Michaud, J., Im, D. S., Thangada, S., Xiong, Y., Smith, J. D., et al. (2011). Sphingosine-1-phosphate receptor-2 function in myeloid cells regulates vascular inflammation and atherosclerosis. Arterioscler. Thromb. Vasc. Biol. 31, 81-85. doi: 10.1161/atvbaha.110.213496

Smits, L. P., Kootte, R. S., Levin, E., Prodan, A., Fuentes, S., Zoetendal, E. G., et al. (2018). Effect of vegan fecal microbiota transplantation on carnitine- and choline-derived trimethylamine- $\mathrm{N}$-oxide production and vascular inflammation in patients with metabolic syndrome. J. Am. Heart Assoc. 7:e008342. doi: 10.1161/jaha.117.008342

Staudinger, J. L., Goodwin, B., Jones, S. A., Hawkins-Brown, D., MacKenzie, K. I., LaTour, A., et al. (2001). The nuclear receptor PXR is a lithocholic acid sensor that protects against liver toxicity. Proc. Natl. Acad. Sci. U.S.A. 98, 3369-3374. doi: 10.1073/pnas.051551698

Stoll, L. L., Denning, G. M., and Weintraub, N. L. (2004). Potential role of endotoxin as a proinflammatory mediator of atherosclerosis. Arterioscler. Thromb. Vasc. Biol. 24, 2227-2236. doi: 10.1161/01.ATV.0000147534.69062.dc

Studer, E., Zhou, X., Zhao, R., Wang, Y., Takabe, K., Nagahashi, M., et al. (2012). Conjugated bile acids activate the sphingosine-1-phosphate receptor 2 in primary rodent hepatocytes. Hepatology 55, 267-276. doi: 10.1002/hep.24681

Subah Packer, C. (2007). Estrogen protection, oxidized LDL, endothelial dysfunction and vasorelaxation in cardiovascular disease: new insights into a complex issue. Cardiovasc. Res. 73, 6-7. doi: 10.1016/j.cardiores.2006.11.013

Sui, Y., Xu, J., Rios-Pilier, J., and Zhou, C. (2011). Deficiency of PXR decreases atherosclerosis in apoE-deficient mice. J. Lipid Res. 52, 1652-1659. doi: 10.1194/ jlr.M017376

Szeto, F. L., Reardon, C. A., Yoon, D., Wang, Y., Wong, K. E., Chen, Y., et al. (2012). Vitamin D receptor signaling inhibits atherosclerosis in mice. Mol. Endocrinol. 26, 1091-1101. doi: 10.1210/me.2011-1329

Tan, J. K., McKenzie, C., Marino, E., Macia, L., and Mackay, C. R. (2017). Metabolite-sensing $\mathrm{g}$ protein-coupled receptors-facilitators of diet-related immune regulation. Annu. Rev. Immunol. 35, 371-402. doi: 10.1146/annurevimmunol-051116-052235

Tang, W. H., Kitai, T., and Hazen, S. L. (2017). Gut microbiota in cardiovascular health and disease. Circ. Res. 120, 1183-1196. doi: 10.1161/circresaha.117. 309715

Tang, W. H., Wang, Z., Levison, B. S., Koeth, R. A., Britt, E. B., Fu, X., et al. (2013). Intestinal microbial metabolism of phosphatidylcholine and cardiovascular risk. N. Engl. J. Med. 368, 1575-1584. doi: 10.1056/NEJMoa1109400

Tilg, H., Adolph, T. E., Gerner, R. R., and Moschen, A. R. (2018). The intestinal microbiota in colorectal cancer. Cancer Cell 33, 954-964. doi: 10.1016/j.ccell. 2018.03.004

Townsend, M. K., Aschard, H., De Vivo, I., Michels, K. B., and Kraft, P. (2016). Genomics, telomere length, epigenetics, and metabolomics in the nurses', health studies. Am. J. Public Health 106, 1663-1668. doi: 10.2105/ajph.2016. 303344

Tremaroli, V., and Backhed, F. (2012). Functional interactions between the gut microbiota and host metabolism. Nature 489, 242-249. doi: 10.1038/ nature 11552

Troseid, M., Ueland, T., Hov, J. R., Svardal, A., Gregersen, I., Dahl, C. P., et al. (2015). Microbiota-dependent metabolite trimethylamine-Noxide is associated with disease severity and survival of patients with chronic heart failure. J. Int. Med. 277, 717-726. doi: 10.1111/joim. 12328

Vrieze, A., Van Nood, E., Holleman, F., Salojarvi, J., Kootte, R. S., Bartelsman, J. F., et al. (2012). Transfer of intestinal microbiota from lean donors increases insulin sensitivity in individuals with metabolic syndrome. Gastroenterology 143, 913.e7-916.e7. doi: 10.1053/j.gastro.2012.06.031

Wahlstrom, A., Sayin, S. I., Marschall, H. U., and Backhed, F. (2016). Intestinal crosstalk between bile acids and microbiota and its impact on host metabolism. Cell Metab. 24, 41-50. doi: 10.1016/j.cmet.2016.05.005

Wang, H., Zhang, W., Zuo, L., Dong, J., Zhu, W., Li, Y., et al. (2014). Intestinal dysbacteriosis contributes to decreased intestinal mucosal barrier function and increased bacterial translocation. Lett. Appl. Microbiol. 58, 384-392. doi: 10. 1111/lam.12201

Wang, Z., Tang, W. H., Buffa, J. A., Fu, X., Britt, E. B., Koeth, R. A., et al. (2014). Prognostic value of choline and betaine depends on intestinal microbiotagenerated metabolite trimethylamine-N-oxide. Eur. Heart J. 35, 904-910. doi: 10.1093/eurheartj/ehu002

Wang, Z., Klipfell, E., Bennett, B. J., Koeth, R., Levison, B. S., Dugar, B., et al. (2011). Gut flora metabolism of phosphatidylcholine promotes cardiovascular disease. Nature 472, 57-63. doi: 10.1038/nature09922

Warrier, M., Shih, D. M., Burrows, A. C., Ferguson, D., Gromovsky, A. D., Brown, A. L., et al. (2015). The TMAO-generating enzyme flavin monooxygenase 3 is a central regulator of cholesterol balance. Cell Rep. doi: 10.1016/j.celrep.2014.12. 036 [Epub ahead of print].

Watanabe, M., Houten, S. M., Mataki, C., Christoffolete, M. A., Kim, B. W., Sato, H., et al. (2006). Bile acids induce energy expenditure by promoting intracellular thyroid hormone activation. Nature 439, 484-489. doi: 10.1038/ nature 04330 
Watzl, B., Girrbach, S., and Roller, M. (2005). Inulin, oligofructose and immunomodulation. Br. J. Nutr. 93(Suppl. 1), S49-S55. doi: 10.1079/ BJN20041357

Wiedermann, C. J., Kiechl, S., Dunzendorfer, S., Schratzberger, P., Egger, G., Oberhollenzer, F., et al. (1999). Association of endotoxemia with carotid atherosclerosis and cardiovascular disease: prospective results from the Bruneck Study. J. Am. Coll. Cardiol. 34, 1975-1981. doi: 10.1016/S0735-1097(99)004489

Xu, H., Barnes, G. T., Yang, Q., Tan, G., Yang, D., Chou, C. J., et al. (2003). Chronic inflammation in fat plays a crucial role in the development of obesity-related insulin resistance. J. Clin. Investig. 112, 1821-1830. doi: 10.1172/JCI200319451

Xu, X. H., Shah, P. K., Faure, E., Equils, O., Thomas, L., Fishbein, M. C., et al. (2001). Toll-like receptor-4 is expressed by macrophages in murine and human lipid-rich atherosclerotic plaques and upregulated by oxidized LDL. Circulation 104, 3103-3108. doi: 10.1161/hc5001.100631

Yamashiro, K., Tanaka, R., Urabe, T., Ueno, Y., Yamashiro, Y., Nomoto, K., et al. (2017). Gut dysbiosis is associated with metabolism and systemic inflammation in patients with ischemic stroke. PLoS One 12:e0171521. doi: 10.1371/journal. pone.0171521

Yang, T., Santisteban, M. M., Rodriguez, V., Li, E., Ahmari, N., Carvajal, J. M., et al. (2015). Gut dysbiosis is linked to hypertension. Hypertension 65, 1331-1340. doi: 10.1161/hypertensionaha.115.05315

Yoo, J. Y., and Kim, S. S. (2016). Probiotics and prebiotics: present status and future perspectives on metabolic disorders. Nutrients 8:173. doi: 10.3390/nu8030173

Zhang, K., Zhang, L., Zhou, B., Wang, Y., Song, Y., Rao, L., et al. (2012). Lack of association between TLR4 Asp299Gly polymorphism and atherosclerosis: evidence from meta-analysis. Thromb. Res. 130, e203-e208. doi: 10.1016/j. thromres.2012.07.008

Zhang, Y., Wang, X., Vales, C., Lee, F. Y., Lee, H., Lusis, A. J., et al. (2006). FXR deficiency causes reduced atherosclerosis in Ldlr-/- mice. Arterioscler. Thromb. Vasc. Biol. 26, 2316-2321. doi: 10.1161/01.atv.0000235697.35431.05

Zheng, X., Huang, F., Zhao, A., Lei, S., Zhang, Y., Xie, G., et al. (2017). Bile acid is a significant host factor shaping the gut microbiome of diet-induced obese mice. BMC Biol. 15:120. doi: 10.1186/s12915-0170462-7
Zheng, Y., Li, Y., Rimm, E. B., Hu, F. B., Albert, C. M., Rexrode, K. M., et al. (2016). Dietary phosphatidylcholine and risk of all-cause and cardiovascularspecific mortality among US women and men. Am. J. Clin. Nutr. 104:173. doi: 10.3945/ajen.116.131771

Zhou, C., King, N., Chen, K. Y., and Breslow, J. L. (2009). Activation of PXR induces hypercholesterolemia in wild-type and accelerates atherosclerosis in apoE deficient mice. J. Lipid Res. 50, 2004-2013. doi: 10.1194/jlr.M800608JLR200

Zhu, L., Baker, S. S., Gill, C., Liu, W., Alkhouri, R., Baker, R. D., et al. (2013). Characterization of gut microbiomes in nonalcoholic steatohepatitis (NASH) patients: a connection between endogenous alcohol and NASH. Hepatology 57, 601-609. doi: 10.1002/hep.26093

Zhu, L., Zhang, D., Zhu, H., Zhu, J., Weng, S., Dong, L., et al. (2018). Berberine treatment increases Akkermansia in the gut and improves high-fat diet-induced atherosclerosis in Apoe(-/-) mice. Atherosclerosis 268, 117-126. doi: 10.1016/j. atherosclerosis.2017.11.023

Zhu, W., Gregory, J. C., Org, E., Buffa, J. A., Gupta, N., Wang, Z., et al. (2016). Gut microbial metabolite TMAO enhances platelet hyperreactivity and thrombosis risk. Cell 165, 111-124. doi: 10.1016/j.cell.2016. 02.011

Zhu, W., Wang, Z., Tang, W. H. W., and Hazen, S. L. (2017). Gut microbegenerated trimethylamine $\mathrm{N}$-oxide from dietary choline is prothrombotic in subjects. Circulation 135, 1671-1673. doi: 10.1161/circulationaha.116. 025338

Conflict of Interest Statement: The authors declare that the research was conducted in the absence of any commercial or financial relationships that could be construed as a potential conflict of interest.

Copyright (C) $2018 \mathrm{Ma}$ and Li. This is an open-access article distributed under the terms of the Creative Commons Attribution License (CC BY). The use, distribution or reproduction in other forums is permitted, provided the original author(s) and the copyright owner(s) are credited and that the original publication in this journal is cited, in accordance with accepted academic practice. No use, distribution or reproduction is permitted which does not comply with these terms. 